\title{
Short history of laser development
}

Jeff Hecht

525 Auburn Street

Auburndale, Massachusetts 02466

E-mail: jeff@jeffhecht.com

\begin{abstract}
Half a century has passed since Theodore Maiman's small ruby rod crossed the threshold of laser emission. The breakthrough demonstration earned headlines, but in the early years the laser was called "a solution looking for a problem," and there was a germ of truth in the joke. Years of development since then have vastly improved laser performance, and tremendously increased their variety, earning lasers important roles in scientific research, consumer products, telecommunications, engineering, medicine, materials working, and a host of other applications. This article reviews the highlights of those developments and puts them into context, showing how laser technology has evolved to meet application requirements. ๑ 2010 Society of Photo-Optical Instrumentation Engineers. [DOI: 10.1117/1.3483597]
\end{abstract}

Subject terms: lasers; history; laser applications.

Paper 100010SSR received Jan. 5, 2010; revised manuscript received Jun. 11, 2010; accepted for publication Jun. 19, 2010; published online Sep. 1, 2010.

\section{Introduction}

The laser is often grouped with the transistor and the computer as landmark inventions of the mid-20th century. All three technologies had deep conceptual roots, and grew and flowered rapidly in the years after the end of World War II. They benefitted from heavy government and corporate investment in physical research, a rapid growth in the numbers of physicists and engineers, and a legacy of ideas and equipment from the war years. It was an era of widespread technological progress and optimism, tempered by fears that Cold War tensions could lead to nuclear war.

Although the potential of the three technologies seems obvious today, it was not as clear initially. The transistor was first seen as a compact, solid state replacement for vacuum tubes; integrated circuits were invented more than a decade later. Programmable electronic computers initially were thought useful only for scientific research. For its part, the laser was at its birth heralded variously as a sciencefiction death ray ${ }^{1}$ or a higher frequency coherent transmitter for atmospheric communications. ${ }^{2}$

In covering the evolution of laser science and technology, this article concentrates on two interacting series of developments, of laser devices and of laser applications. Inevitably, the two processes interacted. Application developers tested existing laser devices and gave laser developers feedback on new features needed to make applications practical. As applications evolved, their laser requirements also evolved. For example, the requirements of early optical communication systems pushed development of semiconductor diode lasers. Gallium-arsenide diodes sufficed for links of several kilometers between telephone central offices, but when glass fibers were found to transmit better at longer wavelengths, InGaAsP diode lasers were developed for the windows at 1310 and $1550 \mathrm{~nm}$. In this sense, laser technology evolved in response to the economic environment, like other technologies. ${ }^{3}$

Lasers have had a rich and complex history over the

0091-3286/2010/\$25.00 @ 2010 SPIE half-century since Theodore Maiman crossed the threshold of the laser age on May 16, 1960, at Hughes Research Laboratories. This short article cannot cover that history in the detail it deserves. It is impossible to list all significant developments of the past 50 years, or to credit all the people who made important contributions during that time. Instead, I have focused on broad trends in the technology, noting some milestones along the way, and hoping that I have not overlooked too much. The timeline in the Appendix lists key events covered in this article through 2002, but is not intended to be comprehensive.

\section{Background}

The first conceptual building block of the laser was Albert Einstein's 1916 proposal that photons could stimulate emission of identical photons from excited atoms. ${ }^{4}$ Rudolf Ladenburg reported indirect evidence of stimulated emission in 1928. ${ }^{5}$ However, physicists of the time called the effect "negative absorption," and considered it of little practical importance because they expected Boltzmann population distributions to be the norm, with higher energy states inevitably less populated than lower levels.

In 1940, Russian physicist Valentin A. Fabrikant suggested that stimulated emission in a gas discharge might amplify light under suitable conditions. ${ }^{6}$ However, he did not propose a resonator and did not follow up on his proposal for many years. After World War II, Willis Lamb, Jr., and R. C. Retherford realized that nuclear magnetic resonance could produce population inversions ${ }^{7}$ and Edward M. Purcell and Robert V. Pound used the effect to observe stimulated emission of $50-\mathrm{kHz}$ radio waves. ${ }^{8}$

In 1951, Charles H. Townes took the next conceptual step, suggesting that stimulated emission at microwave frequencies could oscillate in a resonant cavity, producing coherent output. In 1954, Townes and his student James Gordon ${ }^{9}$ demonstrated the first microwave maser, directing excited ammonia molecules into a resonant cavity where they oscillated at $24 \mathrm{Ghz} .^{9}$ 


\section{The Laser Concept}

A burst of microwave maser development followed, but some physicists began thinking about extending the maser principle to higher frequencies. With millimeter waves, the terahertz band, and the far IR largely undeveloped, that meant jumping to three to four orders of magnitude in frequency to the optical range. Townes at first dismissed the idea, but by the summer of 1957 he had changed his mind and began investigating the prospects in his typical systematic way. He talked with colleagues at Columbia University and, shortly after the October 4 Sputnik launch, sat down with Gordon Gould, then a 37-year-old doctoral student working under Polykarp Kusch.

At this point Townes had essentially formulated a physics problem-how could one build an optical oscillator to generate coherent light by amplifying stimulated emission? For his dissertation, Gould was using the then-new technique of optical pumping to measure properties of thallium vapor. Townes thought optical pumping might produce the population inversion he needed for his optical maser, so he asked Gould about his thallium lamp. Gould, in turn, asked Townes about his project, and when Townes told him, Gould said he had been wondering about the same thing. After a second conversation, the two went off separately to try to solve the physics problem. Both succeeded. ${ }^{10}$

Gould had always dreamed of being an inventor, and had the advantage of having earlier worked with optics. He holed up in his apartment with a stack of references, coined the word laser for his invention, and sketched out a plan for the now-familiar Fabry-Pérot resonator in a notebook he had notarized on November 13, 1957, shown in Fig. 1. That notebook would become the foundation for a battle over patents, which after 30 years finally made Gould a multimillionaire. ${ }^{11}$

Townes teamed with Arthur Schawlow, a former Columbia colleague who had married Townes's sister and had worked on optical spectroscopy. Together they wrote a detailed proposal for what they called an "optical maser" that Physical Review published ${ }^{12}$ in December 1958.

\section{The Laser Race}

The race was on to make a laser, but two crucial questions remained unanswered: how to excite a population inversion and what to use as an active medium. Schawlow and Townes had concentrated on optical pumping of a vaporized alkali metal such as potassium with a lamp emitting on lines of the same element. Their paper also mentioned optical pumping of an impurity atom in a transparent solid, but they thought that would require a light source that precisely matched an absorption line. Ali Javan at Bell Labs proposed exciting a gas with an electric discharge, and settled on a system in which the discharge excited helium atoms, which transferred energy to the neon atoms that emitted light. ${ }^{13}$ Gould included those possibilities in a laundry list of potential laser transitions in his patent application. ${ }^{14}$ However, experimental progress was slow.

Maiman began investigating ruby because he knew the material well from having designed a compact microwave maser using ruby crystals. Schawlow had decided ruby would not work in lasers because it was a three-level system, with its red line dropping to the ground state, and

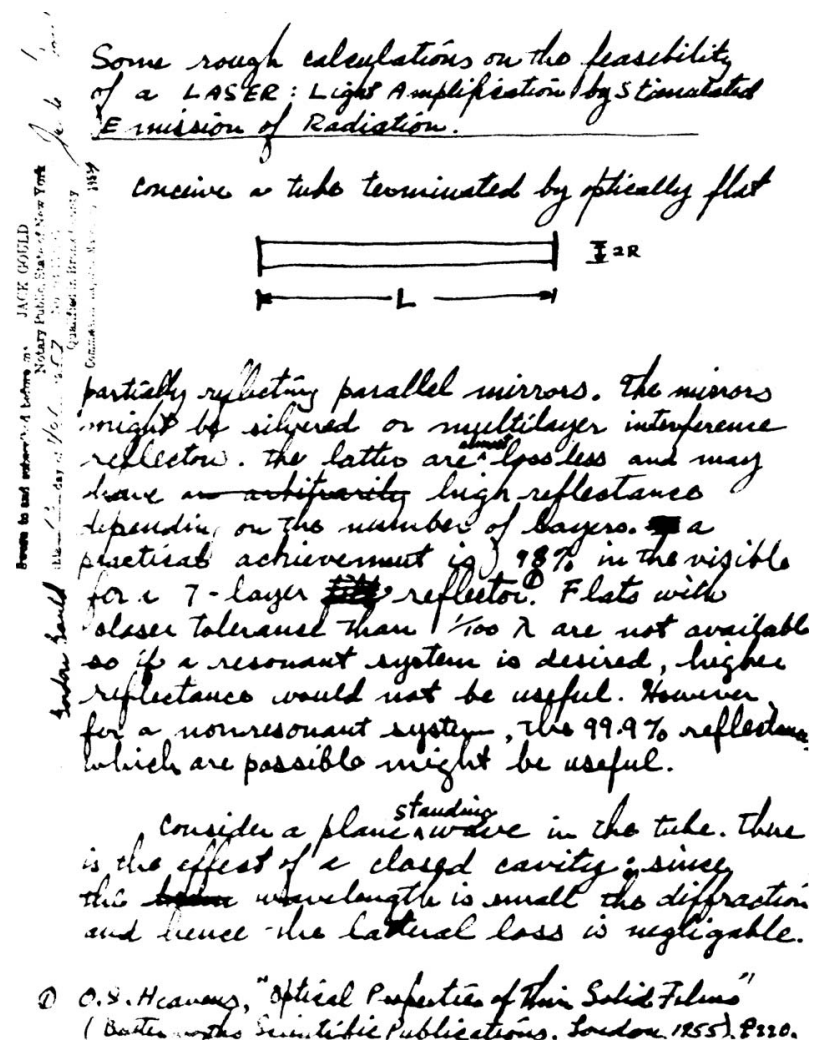

Fig. 1 First page of Gordon Gould's November 1957 notebook shows his sketch of a Fabry-Pérot laser resonator and comments about resonator mirrors. (Courtesy of Gordon Gould)

because other measurements had shown its red fluorescence was inefficient. Maiman made his own measurements and found that ruby fluorescence actually was quite efficient. ${ }^{15}$ He also decided that intense lamps emitting white light could raise the chromium atoms in ruby to the excited laser level, and that excitation would be easiest with the bright pulses from a flashlamp.

His ruby laser [shown in Fig. 2(a)] looks deceptively

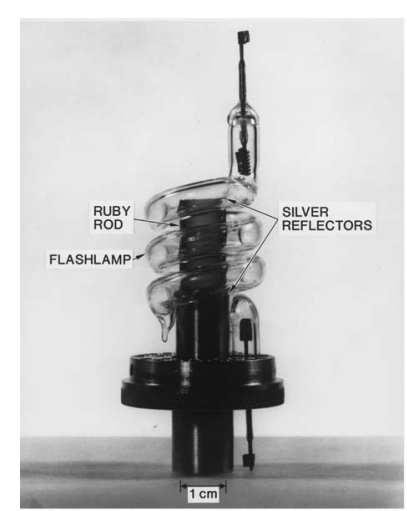

(a)

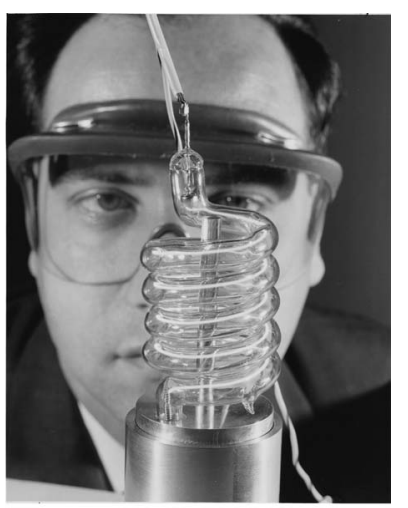

(b)
Fig. 2 (a) Theodore Maiman's first laser, removed from aluminum cylinder used during operation, and (b) photo of Maiman behind a larger ruby laser, handed out at the Hughes press conference announcing the laser. The photographer insisted on posing Maiman with the larger laser, and initially many thought this was the first laser. (Courtesy of Kathleen Maiman) 


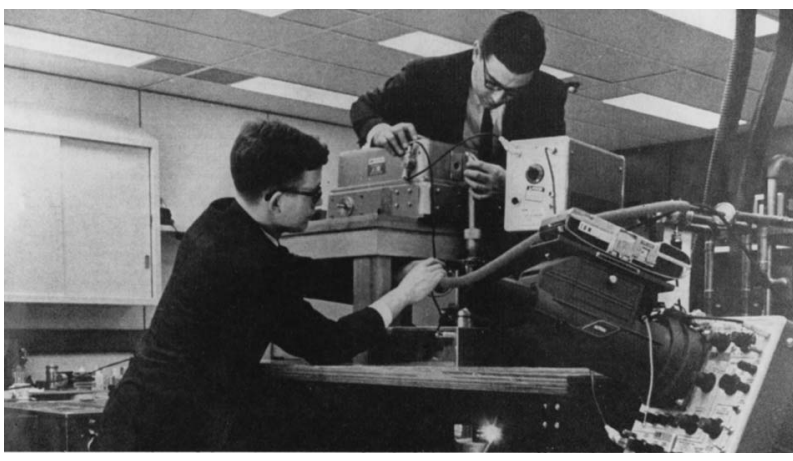

Fig. 3 Peter Sorokin (left) and Mirek Stevenson (right) adjust their cryogenically cooled uranium- $\mathrm{CsF}_{2}$ laser at the IBM T. J. Watson Research Center. (Courtesy of IBM)

simple. By slipping a small ruby rod inside the coil of a photographic flashlamp, and enclosing the assembly in a reflective cylinder, he focused intense pump light into the ruby rod. He tested his design on May 16, 1960, by gradually increasing the voltage applied to the flashlamp until the pulses of red light grew sharply brighter and their time and spectral profiles showed the changes expected from a laser.

Hughes chose to announce the laser at a July 7, 1960, press conference in New York after Physical Review Letters summarily rejected Maiman's report of the discovery. Some researchers doubted the claims, but Gould's coworkers at TRG Inc. and Schawlow's coworkers at Bell Labs built their own working ruby lasers within weeks, although they had only seen the Hughes press release photo in Fig. 2(b), which didn't show Maiman's first laser. ${ }^{16}$ Maiman published a very short description of his experiment in Nature, ${ }^{17}$ but the most complete account of his experiments did not appear ${ }^{18}$ until 1961.

\section{More Lasers}

The ruby laser stunned most other laser researchers, but it inspired Peter Sorokin and Mirek Stevenson. They had laser rods made from crystals of calcium fluoride doped with uranium, which they had earlier identified as a potential four-level laser system, and pumped them with a flashlamp to make the second laser, the first four-level system ${ }^{19}$ (shown in Fig. 3). Then they ${ }^{20}$ made the third laser by flashlamp-pumping another four-level system, samariumdoped $\mathrm{CaF}_{2}$. Unlike ruby, neither found any practical applications; both required cryogenic cooling and emitted in the IR.

An interesting historical footnote is the red ruby laser, demonstrated independently by Schawlow at Bell and by Irwin Wieder at Varian Associates, whose papers both arrived at Physical Review Letters on December 19, 1960, and were published in the same issue. ${ }^{21}$ Maiman's laser used "pink" ruby, in which the chromium concentration was low enough that chromium atoms did not interact with each other. At higher concentrations the chromium atoms gave the ruby crystal a deeper red appearance, and their interaction created a four-level laser system with emission lines at 701.0 and $704.1 \mathrm{~nm}$ - if the material was cooled to liquid nitrogen temperature. Both Schawlow and Wieder demonstrated flashlamp-pumped lasing on the red ruby la-

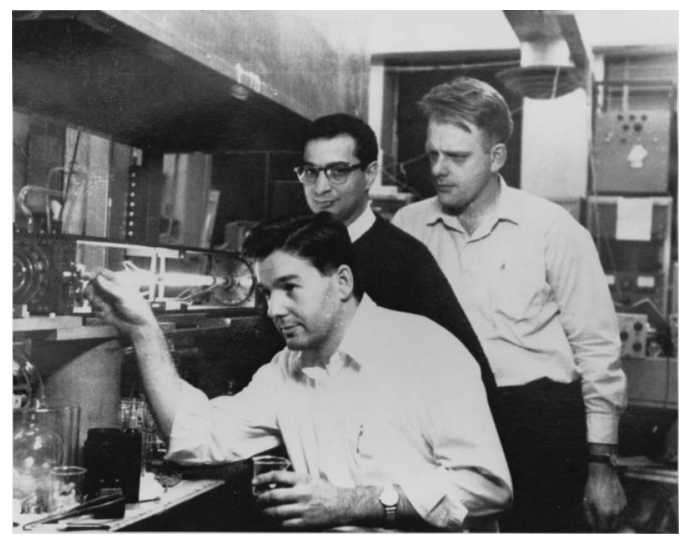

Fig. 4 Donald Herriott, Ali Javan, and William Bennett pose with the first helium-neon laser at Bell Labs. The beaker in Herriott's hand contains a celebratory liquid. (Courtesy of William Bennett)

ser, but like the uranium and samarium lasers, red ruby never proved practical.

Javan, William Bennett, and Donald Herriott needed to make and align a high-reflectivity cavity about a meter long to get the low-gain helium-neon laser running, and they finally succeeded on the snowy afternoon of December 12, 1960. Operating on a $1.15-\mu \mathrm{m}$ line chosen for its high gain, it was the first continuous-wave laser and the first gas laser. $^{22}$ The first in a large family of discharge excited gas lasers, their helium-neon laser (shown in Fig. 4) was closer to the original concept of a continuous coherent optical oscillator than the earlier pulsed solid state lasers, although at nearly a meter long it was much longer than the $10-\mathrm{cm}$ cavity Schawlow and Townes had considered in their analysis.

Other low-gain continuous-wave lasers would come more easily. Gary Boyd and James Gordon designed the confocal resonator, and its curved mirrors greatly eased cavity alignment. ${ }^{23}$ Once the helium-neon laser became available, its coherent beam further eased cavity alignment, and by early 1963 Bell Labs identified many noble-gas laser lines in gas discharges.

The most important of those gas-laser lines was the 632.8-nm line of helium-neon, which Alan White and Dane Rigden developed at Bell Labs after building an enhanced copy of the 1.15- $\mu \mathrm{m}$ helium-neon laser for the Army Signal Corps. Working evenings and weekends, they further refined the helium-neon laser. After they put on a pair of red mirrors, White recalled, "We put the first gas in the tube, lined up the concave mirrors, and bingo, it went." 24 It was the first continuous-wave laser with a visible beam, and it excited everyone when reported ${ }^{25}$ in 1962 . Figure 5 shows White behind the laser.

Earlier, Leo F. Johnson and Kurt Nassau of Bell made a milestone demonstration of the first neodymium-doped solid state laser emitting on the now-standard $1.06-\mu \mathrm{m}$ transition, using a calcium-tungstate host. ${ }^{26}$ Later they, Boyd, and R. R. Soden demonstrated continuous-wave laser action in the same material at room temperature-the first from a solid. ${ }^{27}$ Many other hosts were tested and other rare-earth emitters, but not until 1964 did Joseph E. Geusic, 


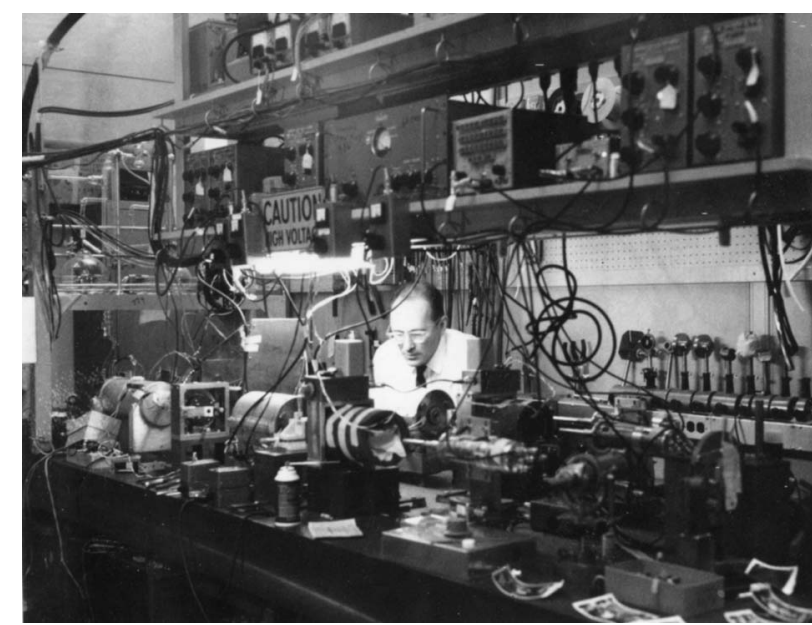

Fig. 5 Alan White working behind the optical bench holding the first red helium-neon laser at Bell Labs. (Courtesy of Alan White)

H. W. Marcos, and LeGrand van Uitert of Bell demonstrate lasing in Nd-YAG, which would become the dominant solid state laser. ${ }^{28}$

Meanwhile, Elias Snitzer was testing prospects for laser action from glasses doped with rare earths at American Optical, a major maker of optical glass and an early developer of bundled optical fibers. He measured emission from the elements that fluoresced in the IR-neodymium, praseodymium, holmium, erbium, and thulium-and found that neodymium was by far the strongest emitter. ${ }^{29}$ In 1961 he demonstrated the first neodymium-glass laser in a millimeter-scale rod with the neodymium glass in a highindex core, making it essentially the first fiber laser. ${ }^{30}$ Glass laser developers moved on to thicker rods in quest for higher power, and wouldn't return to fiber lasers for many years, but in 1964, Charles Koester and Snitzer demonstrated the first fiber amplifier, using a spring-shaped coil of fiber he slipped around a linear flashlamp, echoing Maiman's ruby laser design. ${ }^{31}$

Optical pumping of alkali-metal vapors was all but completely abandoned as too cumbersome, but in 1962 Paul Rabinowitz, Steve Jacobs, and Gould reported laser oscillation on a $7.18-\mu \mathrm{m}$ cesium line. ${ }^{32}$

\section{Semiconductor Diode Lasers}

As early as 1953, John von Neumann sketched out an idea for producing stimulated emission in semiconductors, but his proposal was not published until nearly 30 years after his death. ${ }^{33}$ Nikolai Basov and Pierre Aigrain ${ }^{34}$ made independent proposals in the late 1950s. However, details were hazy, and it took studies of light emission at $p$ - $n$ junctions to launch the semiconductor diode laser.

Henry J. Round first observed ${ }^{35}$ light emission from semiconductor junctions in 1907, but the effect was largely ignored until invention of the transistor led to research on III-V compounds. Rubin Braunstein observed ${ }^{36}$ light emission from junctions in gallium arsenide, indium phosphide, and indium antimonide in 1955. That suggested III-V junctions as laser candidates, but their observed emission efficiency was very low, and the importance of direct bandgaps was not clearly understood, so progress was very slow.

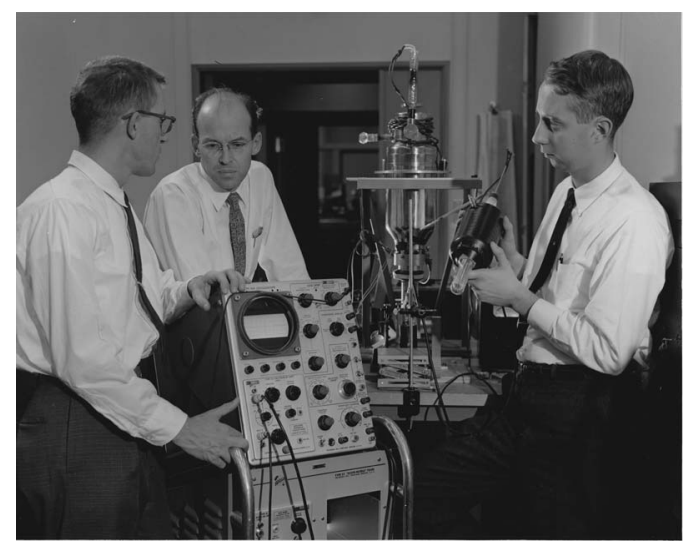

Fig. 6 Gunther Fenner, Robert Hall, and Jack Kingsley show the equipment they used to test the first diode laser at General Electric. (Courtesy of General Electric Research \& Development Center)

That changed in 1962. First, Sumner Mayburg at GTE Laboratories and Jacques Pankove at RCA Labs separately observed bright emission from cryogenically cooled junctions. Then Robert Rediker, Ted Quist, and Robert J. Keyes of MIT Lincoln Laboratory found that diffusing zinc impurities to form a junction dramatically increased the recombination radiation from GaAs LEDs cooled to liquid nitrogen. ${ }^{37}$ One member of the audience at the July 1962 Solid State Device Research Conference was so amazed by the high efficiency that he said it violated the second law of thermodynamics. Keyes apologized, tongue in cheek, but the results were real, setting power and efficiency records for LEDs. ${ }^{38}$

Another person in the audience, Robert N. Hall, quickly realized the implications for lasers, and enlisted colleagues at the General Electric R\&D Laboratory in Schenectady, New York, to help him make a GaAs diode laser. It took them just over two months to make a diode laser that lased when microsecond current pulses were fired through it at liquid-nitrogen temperature in the setup shown ${ }^{39}$ in Fig. 6. Marshall Nathan at the IBM Watson Research Center and the Lincoln Lab group operated their own GaAs lasers soon afterward. ${ }^{40}$ Nick Holonyak Jr. added phosphorous to GaAs to make a red-emitting GaAsP diode laser at GE's Syracuse, New York, laboratory (see Ref. 41).

Although diode lasers were a major breakthrough, all were wide-area homojunction devices, which operated only when cooled to liquid nitrogen temperature and driven above threshold by powerful current pulses. It would take several years before they could emit continuously at room temperature, as necessary for most applications.

\section{First Laser Companies}

Companies old and new were quick to get into the laser market, either selling laser products commercially or doing contract research and development. This included some companies involved in early laser research, notably Hughes Aircraft, American Optical, TRG (officially Technical Research Group), AT\&T (through Bell Labs), and Raytheon. Other established companies that became involved in lasers very early included Sylvania, Martin Marietta, RCA, and Perkin-Elmer. As a regulated telephone monopoly, AT\&T 


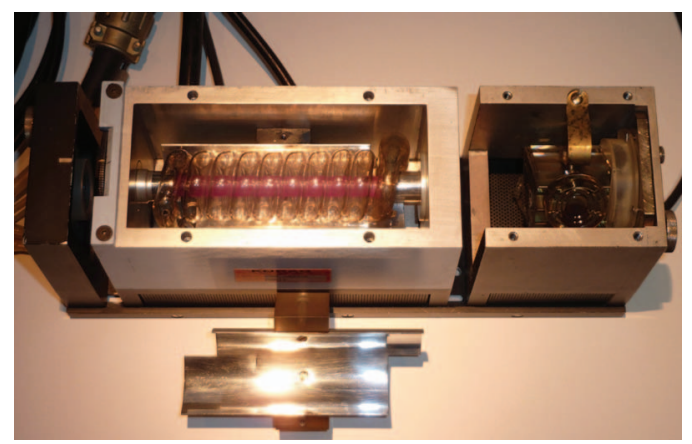

Fig. 7 Korad's first commercial ruby laser, serial \#001 of model $\mathrm{RL}-4 \mathrm{KCS}$. The box at the right is a liquid $Q$ switch. Comparison with Fig. 2(a) shows that Maiman's original design has been modified by using a longer flashlamp with more coils and a longer rod. (Courtesy of anonymous reviewer)

was required by legal agreements to license its patents to other companies, constraining its role in the laser industry.

The new technology also launched a wave of small companies. Maiman was one of the first, initially setting up a laser group at a short-lived company called Quantatron in Santa Monica, California, then taking his laser group to form the core of Korad Inc., also in Santa Monica, with funding from Union Carbide. ${ }^{42}$ Korad soon began making ruby lasers based on Maiman's design, as shown in Fig. 7. Lowell Cross, Lee Cross (no relation), and Doug Linn founded Trion Instruments Inc. in Ann Arbor, Michigan, in 1961 to build ruby lasers they had developed on the side while working at the University of Michigan's Willow Run Laboratory. ${ }^{43}$ Lear Seigler bought Trion in 1962.

Herbert Dwight, Earl Bell, and Robert Rempel formed Spectra-Physics, which initially teamed with Perkin-Elmer to manufacture helium-neon lasers. They first offered a $1.15-\mu \mathrm{m}$ model selling for about $\$ 8000$ in March 1962. Six months later they introduced a red version and sales jumped. The following year the two companies ended their agreement after selling 75 lasers. ${ }^{44}$ An important competitor was Optics Technology, formed to make fiber optics in 1960 by Narinder Kapany, who soon decided to make ruby and helium-neon lasers as well.

\section{Early Laser Applications}

Soon after Maiman built the first laser, his assistant Irnee D'Haenens joked that the laser was "a solution looking for a problem." Like any successful wisecrack, it contained a bit of truth. The laser was not a device invented to fill specific application requirements, like the telephone. It was more a discovery than an invention, a way to generate coherent light that laser developers expected would find applications in broad areas, such as research or communications.

Bell Labs management saw coherent light as a technology that increase the capacity of the Bell System's backbone telephone network, which in 1960 consisted of chains of microwave relay towers. Plans were already in the works to upgrade the long-distance network to buried millimeter waveguides carrying signals at $60 \mathrm{GHz}$, but Bell had longterm plans to upgrade the telephone system from voice to video, which would require much more bandwidth. Optical frequencies were more than a thousand times higher, so they promised the needed bandwidth.

The Pentagon wanted a new generation of weapons. Deeply unsettled by the 1957 Sputnik launch, the Eisenhower administration created the Advanced Research Projects Agency (ARPA, now DARPA) to invest in highrisk, high-payoff research that other military research agencies had been unwilling to support. Soon after ARPA opened its doors, its first director, Roy Johnson, told Congress he would fund anything that might reduce the threat of nuclear attack, even "death rays." 45 When TRG asked for $\$ 300,000$ to try to build a laser using Gould's ideas, ARPA instead gave them $\$ 999,000$, hoping for applications in target designation and communications, as well as in missile defense. ${ }^{46}$

Increasing the number of communication channels was one of the five potential applications Maiman mentioned at the 1960 press conference announcing the laser. The other four were

1. true amplification of light,

2. probing matter for basic research,

3. high-power beams for space communications, and

4. concentrating light for industry, chemistry, and medicine.

Maiman tried to avoid reporters' questions about weapons at the press conference, but finally admitted he couldn't rule them out, and was dismayed to be greeted on his return to California by a 2-in. red headline on the front page of the Los Angeles Herald, "L. A. man discovers science-fiction death ray." 47

Afterward, engineers and physicists began testing copies of Maiman's ruby laser is labs around the world. They quickly found that pulsed lasers could punch holes through thin metal sheets, and briefly measured laser pulse power in "gillettes," the number of razor blades it could penetrate.

Physicians began testing lasers to see if they could treat ailments better than other light sources, particularly in dermatology and ophthalmology, where light was already widely used. The first important laser success was in rubylaser treatment of detached retinas. Previously, ophthalmologists had focused light from 1000-W arc lamps into the eye for 1-s intervals to form scars attaching the retina to the eyeball. The procedure had to be re-engineered to use millisecond laser pulses, but it worked in rabbits, and ophthalmologist Charles J. Campbell treated the first human patient at the Harkness Eye Institute of Columbia University $^{48}$ on November 22, 1961. About a week later, Christian Zweng performed a similar operation in Palo Alto, California. Both operations were successful.

Physicists focused laser beams to high intensity to study laser-matter interactions. In 1961, Peter Franken focused 3-J ruby pulses into quartz and generated the 347.2-nm second harmonic, which appeared as a faint spot on a photo recorded after passing the light through a spectrometer. ${ }^{49}$ $\mathrm{He}$ and three University of Michigan colleagues called the faint spot an "unambiguous indication of second harmonic," but that didn't stop someone at Physical Review Letters from thinking the spot was a flaw in the photo and editing it out. The Lawrence Livermore National Labora- 
tory wondered about prospects for laser-induced nuclear fusion, and in 1962 formed a group to study the prospects seriously. 50

\section{9 "The Incredible Laser"}

As new types of lasers and new applications emerged, the laser caught the public imagination. It had the good fortune to be invented when the public welcomed new technology with open arms and optimism. The United States was in the midst of a technology boom, and with the notable exception of nuclear weapons, the public generally saw new technology as bringing hope.

A 1962 article titled “The Incredible Laser" gives a snapshot of the laser's public image at the time. It promised "an exciting report on science's new 'Aladdin's lamp.' It can light up the moon, kill instantly, or perform miracle surgery." Author Stuart Loory cited the laser eye surgery, performed just a year earlier, and would later become a respected journalist, earning a place on Richard Nixon's "enemies" list and later a professorship. ${ }^{51}$ Yet at the time he was caught up in the wave of laser over-enthusiasm, writing: "The laser may have greater impact than any discovery so far in the burgeoning field of electronics, which has already brought us radar, transistors, satellite tracking networks, TV. The technological revolution it brings about may dwarf any in the past." 52

Loory quoted Air Force Chief of Staff General Curtis LeMay, extolling the prospects for laser nuclear defense. He cited an Army "death-ray gun [that] would be small enough to be carried or worn as a side-arm-just like the 'ray guns' of so many movies and adventure strips." $\mathrm{He}$ reported that $95 \%$ of government laser research money went to military projects, many classified, but the government wasn't just building death rays. Market analysts predicted laser radars on the battlefield by 1964, and laser power transmission from the ground to satellites by 1965 .

Art Schawlow saw the article and taped a copy to his laboratory door at Stanford University, with a note saying "For credible lasers, see inside" (shown in Fig. 8).

\section{Holography}

Most early laser applications were logical extensions of other uses of light, taking advantage of the good behavior of the coherent, monochromatic, and highly directional nature of a laser beam. The first big surprise was holography, and that, too, depended on the good behavior of laser photons-specifically the long coherence length of red helium-neon lasers.

Dennis Gabor invented holography in the late 1940s as a wavefront reconstruction technique to improve electron microscope images. ${ }^{53}$ His early experiments worked, but because he recorded them with a single beam, the images were small, poor in quality, and limited to two dimensions. He and a small group of others spent several years trying to improve image quality, but by 1957 they had largely given up.

Emmett Leith initially was unaware of Gabor's work when he reinvented wavefront reconstruction at the University of Michigan's Willow Run Laboratory. In 1955 he had invented optical signal processing, which used coherent optics to generate images from synthetic aperture radar data. That required only minimal coherence in one dimension, so

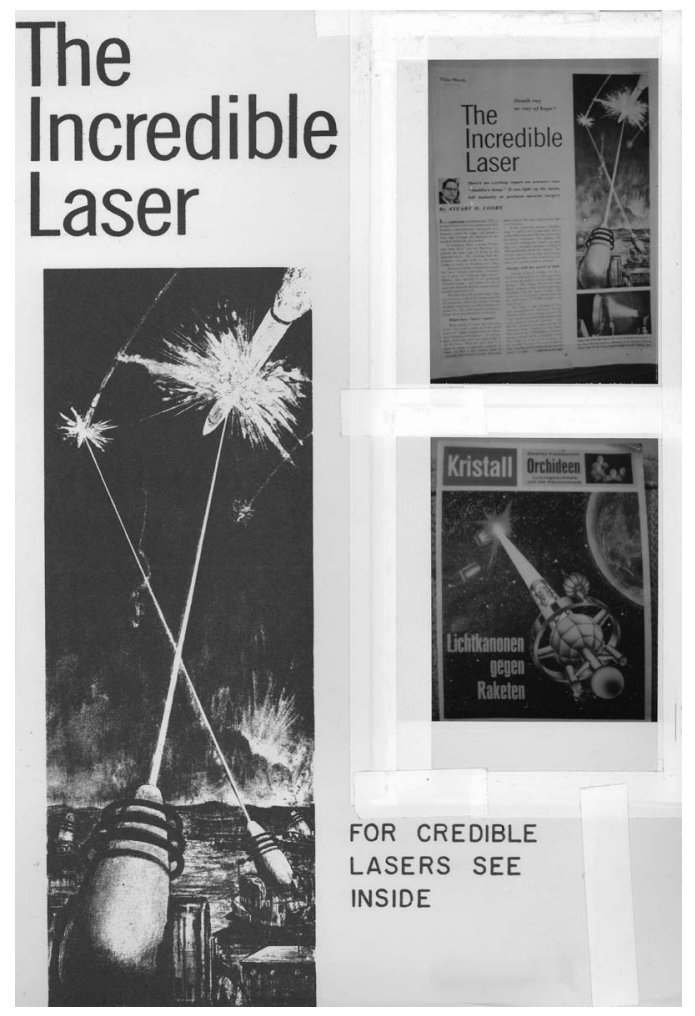

Fig. 8 Annoyed by wild press reports about the incredible laser, Art Schawlow posted samples on the door of his Stanford Laboratory with a note saying "For credible lasers, see inside." Note that the laser cannons at lower right have rings around them, resembling the coils of Maiman's flashlamp. (Courtesy of Arthur Schawlow)

he used high-pressure mercury arc lamps with 5-nm spectral width. After developing the technique, Leith realized it was replicating the radar wavefront on the scale of optical wavelengths, and developed an optical theory of synthetic aperture radar. In October 1956 he discovered Gabor's work and realized it strongly paralleled his.

In 1960, Leith and Juris Upatnieks turned from radar to optical holography and made the crucial step from on-axis holography to off-axis holography, which uses two beams to reconstruct images, avoiding the twin-image problem that had plagued Gabor. They used mercury lamps to record the first off-axis holograms of photographic transparencies, which were much sharper than Gabor's on-axis holograms. ${ }^{54}$ After an 18-month interruption while Upatnieks served in the military, they shifted to one of the first red helium-neon lasers from Spectra-Physics and PerkinElmer because its higher intensity made experiments easier. They first made holograms of transparencies, then found the laser's long coherence length let them record holograms of 3-D objects.

Early red helium-neon lasers emitted in multimode, and had to be stabilized to record good 3-D images. They didn't see the 3-D effect clearly at first because their images were only about an inch on a side, but shifting to $4-\times 5$-in. photographic plates made a dramatic difference. "Only then did we see what the world had never before seen. It was incredible, just totally incredible. It was the one thing that excited us the most," Leith recalled in $1986 .{ }^{55}$ 


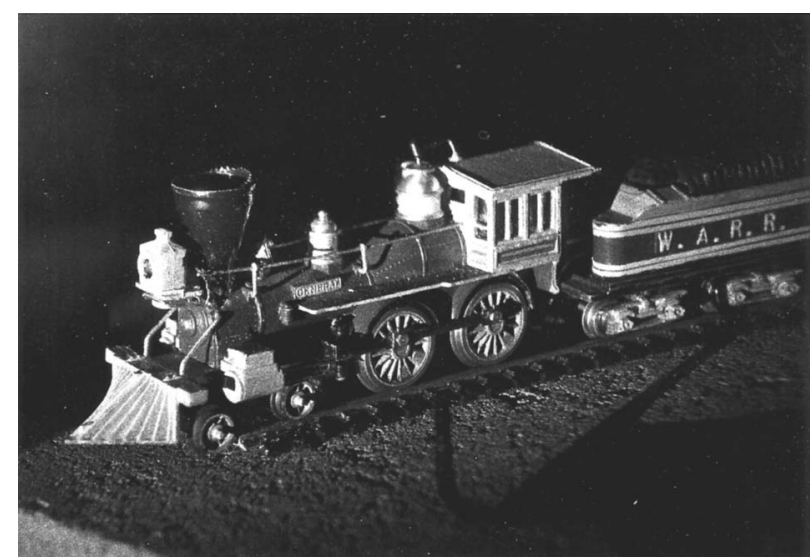

Fig. 9 Three-dimensional laser hologram of a toy train, recorded by Emmett Leith and Juris Upatnieks. (Courtesy of Juris Upatnieks)

Their results also excited the lab, and attendees at the Spring 1964 meeting of the Optical Society of America in Washington, where Upatnieks described their results. ${ }^{56}$ But the high point of the meeting was a display of a hologram of a toy train (shown in Fig. 9) in a hotel suite where Spectra-Physics and Perkin-Elmer were showing red helium-neon lasers. A long line trailed far down the hotel hallway as optics specialists stared in amazement at the laser-reconstructed image of the little $\mathrm{HO}$-gauge train.

\section{Gas Laser Proliferation}

Despite the early hype about laser weapons, by 1963 gaslaser power had stalled out. Bell Labs needed a 15-m tube to obtain 150-mW output from helium-neon. ${ }^{57}$ Kumar Patel decided to look at prospects for laser lines on vibrational transitions of molecules, which he expected to be much more efficient because they were much closer to the ground state than electronic transitions in atoms. He calculated that carbon dioxide should emit at a $10-\mu \mathrm{m}$ line, and observed laser output in his first experiment. ${ }^{58}$

A series of refinements followed. Molecular nitrogen soaked up discharge energy and its first excited state transferred energy to $\mathrm{CO}_{2}$, increasing output from tens of milliwatts to $10 \mathrm{~W}$, then the highest continuous output ever recorded from a laser. Adding helium provided another boost, and by mid-1965 Patel had reached ${ }^{59} 10 \%$ efficiency and continuous power of $200 \mathrm{~W}$. Figure 10 shows him with a flowing-gas $\mathrm{CO}_{2}$ laser in 1967. That was more than needed for laboratory use, so Patel turned to spectroscopy and left higher power $\mathrm{CO}_{2}$ lasers to military researchers with security clearances. ${ }^{60}$ In 1965, Eugene Watson, a cofounder of Spectra-Physics, launched Coherent Radiation Laboratories (now Coherent Inc.) to build commercial $\mathrm{CO}_{2}$ lasers. ${ }^{61}$

An effort by Spectra-Physics cofounder Earl Bell to improve helium-neon lasers led to development of ion lasers. When he added mercury to try to extend the lifetime of a helium-neon laser, Bell saw a green glow near the cathode. Trying to make a laser on the mercury line, he zapped a mercury-laced tube with a high-voltage capacitor and produced pulses in the red-orange and green. ${ }^{62}$ That was exciting because the only practical visible lasers then available were helium-neon and ruby emitting in the red. Theorist Arnold Bloom had expected to find emission from neutral

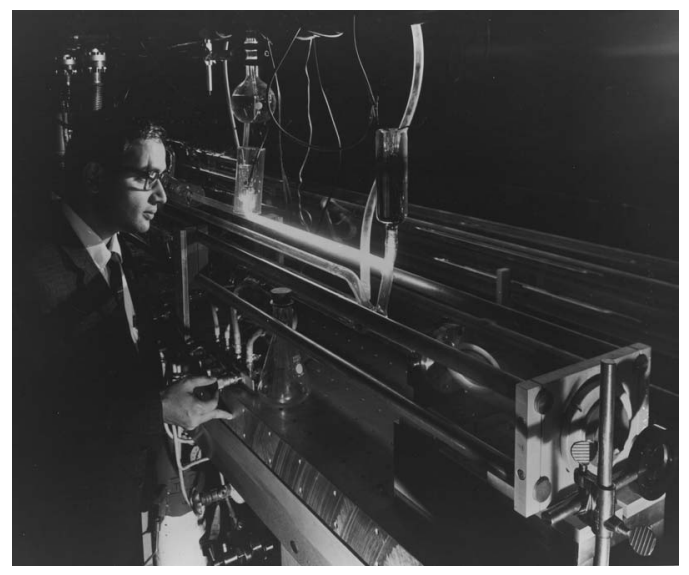

Fig. 10 Kumar Patel with a flowing-gas $\mathrm{CO}_{2}$ laser in 1967. (Courtesy of Bell Labs)

mercury, but when he and Bell looked up the line, they found it was from ionized mercury-a surprise because ion transitions had been thought to be too far above the ground state for laser emission. ${ }^{3}$ The mercury-ion laser did not prove commercially viable, but it did lead others to develop ion lasers that proved important at shorter visible wavelengths.

The first was William Bridges, who was studying energy transfer in a helium-mercury ion laser he had built at Hughes Research Laboratories. He replaced helium with neon, and demonstrated a neon-mercury laser. When he tried argon, he added too much of the gas, and couldn't observe the mercury lines, so he pumped the tube out and started over with helium and mercury. On February 14, 1964 , he was surprised to see a blue line at $488 \mathrm{~nm}$ as well as the mercury lines. ${ }^{64}$ A quick check of emission tables showed the line probably came from ionized argon. When he filled a fresh tube with pure argon, he was able to identify 10 argon emission lines with a high-resolution spectrometer, ${ }^{65}$ although the beam had to be routed through a few hundred feet of hallway separating the laser from the instrument.

Several other groups were working in parallel. Bridges published first, but William Bennett at Yale and Guy Convert at CSF in France discovered the argon lines independently. Bridges also observed laser emission from krypton, xenon, and rare-gas mixtures, but he lacked the ultraviolet optics needed to make a neon-ion laser.

The first round of demonstrations all used pulsed discharges, but Eugene Gordon started work on a continuouswave version at Bell Labs as soon as Bridges told him about the Hughes ion lasers. Within weeks, Gordon stunned Bridges by calling to announce "We've got ours going continuous-wave." 66 Bell had used high-reflectivity cavity mirrors, multiplied current density a factor of 25 by using a 1-mm capillary discharge, and water-cooled an elaborate tube that separated the gas return path from the discharge. ${ }^{67}$ Bridges used the Bell design to make continuous-wave krypton and xenon ion lasers. Although inherently limited in efficiency by their high energy above the ground state, and requiring intense discharge currents, argon-ion lasers became a important product because they offered higher 


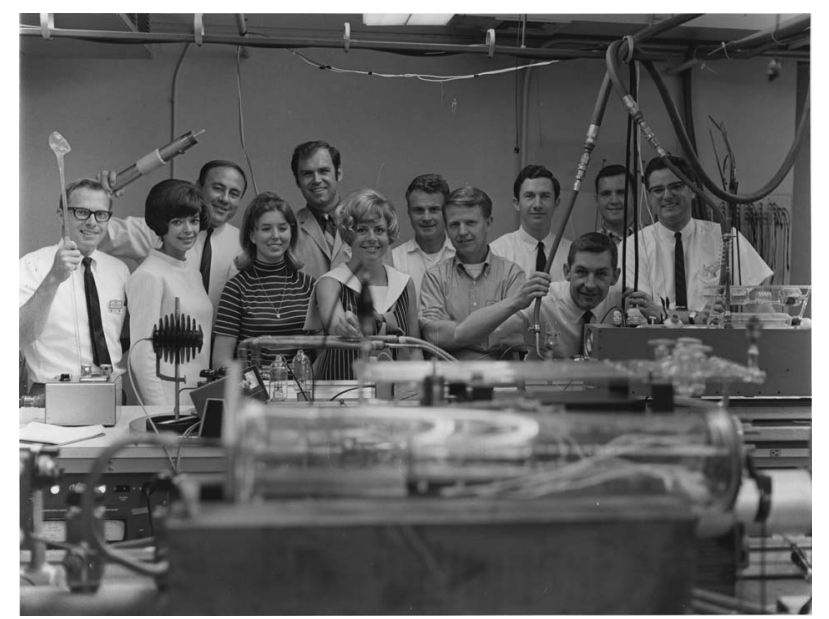

Fig. 11 Ion-laser section at Hughes Research Labs in 1969, with some early laser experiments. From left, Peter O. Clark (with an early $\mathrm{He}-\mathrm{Ne}$ laser), Dorothy LaPierre, Donald C. Forster (with an early metal-ceramic ion laser he designed), Susan Watkins, Michael Barnoski, Diane Orchard, Heintz Tiergartner, Robert B. Hodge, G. Nield Mercer, Howard R. Friedrich, Ronald Smith, and William Bridges. (Courtesy HRL)

powers and shorter wavelengths than previously available in the visible. By 1969, Hughes had a dozen people in its ion-laser section (shown in Fig. 11).

Two families of metal-vapor lasers also were spinoffs from the helium-mercury laser. Grant Fowles and William Silfvast at the University of Utah initially tried to make a bismuth-vapor laser, but when that didn't work they shifted to zinc and cadmium in early 1965. Zinc first produced blue-green laser emission at $492.4 \mathrm{~nm}$. Cadmium followed, but the familiar 441.6-nm line did not appear until they added helium in later experiments. Both emitted on ionic lines, as did lead and tin. ${ }^{68}$ After moving to Bell Labs in 1967, Silfvast made the helium-cadmium laser emit continuous-wave by running a steady low-current discharge. $^{69}$

Fowles and Silfvast also demonstrated the first in the family of self-terminating pulsed neutral metal lasers, observing a 723-nm line from lead with a gain so high that it oscillated even with mirrors coated to reflect blue light. ${ }^{70}$ Soon afterward, a group at TRG reported similarly selfterminating laser action on the 511- and 578-nm transitions of neutral copper. ${ }^{71}$ Although inherently limited to pulsed operation, the copper-vapor laser would prove important because of its high average power at visible wavelengths.

The mid-1960s also saw the birth of chemical lasers, the family of gas lasers operating on IR transitions of molecules produced by chemical reactions. After discovering that some molecular reaction products emitted infrared light, University of Toronto chemist John Polanyi proposed that effect could be used in a laser. ${ }^{72}$ J. V. V. Kasper and George C. Pimentel ${ }^{73}$ at Berkeley demonstrated the first chemical laser in 1965, using a flashlamp to trigger a chemical reaction between hydrogen and chlorine produced excited hydrogen-chloride molecules which lased at $3.7 \mu \mathrm{m}$.

\section{Dye Lasers}

Another invention of the mid-1960s was the organic dye laser, in which the active medium is a solution containing a dye that fluoresces in the visible or near-IR. Peter Sorokin became interested in dyes after observing fluorescence while testing them for Q-switching ruby lasers. He and John Lankard placed a dye cell in a laser cavity, illuminated it with a ruby laser, and produced a laser beam that burned their photographic film. ${ }^{74}$ Fritz P. Schaefer at the Max Planck Institute independently made a similar ruby-pumped dye laser soon afterward. ${ }^{75}$ Flashlamp pumping followed.

The first dye lasers emitted at a fixed wavelength at the peak of the dye's gain curve. In 1967, Bernard Soffer and B. B. McFarland at Korad replaced the rear cavity mirror in a dye laser with a diffraction grating, which they turned to select a wavelength within the gain curve to oscillate in the laser cavity. ${ }^{76}$ Individual dyes had gain over a range of wavelengths, and many different dyes were available, making dye lasers the first broadly tunable lasers, and leading to major advances in laser spectroscopy.

Another important step came three years later when Benjamin Snavely's group at Eastman Kodak demonstrated a continuous-wave dye laser. ${ }^{77}$ Pumping was with an argonion laser, which at the time was the only continuous-wave laser available with adequate power at dye absorption wavelengths.

\section{Evolution of Solid State Lasers}

Solid state lasers evolved in a number of ways, which often interacted. The choice of pump source and pumping arrangement were critically important, as Maiman's success with the flashlamp illustrated. So were the choice of the light-emitting species, the host material, and the physical configuration of the solid-e.g., whether it was a rod, fiber, slab or some other shape. Application requirements were also important, such as pulsed versus continuous-wave operation, the need for certain wavelengths, and heat dissipation.

In the early days of lasers, choices were limited. The coil-shaped flashlamp Maiman used was replaced for most purposes by one or sometimes two linear pump lamps mounted parallel to the laser rod in an elliptical cavity, but flashlamps were the brightest and best pump sources available because of their high peak power. Intense arc lamps could power continuous-wave emission, but crystalline hosts such as YAG were necessary to dissipate the waste heat deposited in the laser material, and was impractical with some laser ions. Moreover, efficient lamp pumping also required light-emitting species with broad absorption bands matching lamp emission, and neodymium and ruby proved the best matches for emission in the near-IR and visible.

Laser pumping was an alternative for demonstrating laser action in materials with narrow pump lines, but the practical applications were limited by the low efficiency of the pump lasers. Diode lasers offered the potential of higher internal efficiency, and in 1963 Roger Newman ${ }^{78}$ recognized the possibility of diode-laser pumping, observing that neodymium ions in solids strongly absorbed GaAs diode laser emission near $800 \mathrm{~nm}$. The following year, Robert Keyes and Ted Quist ${ }^{79}$ of Lincoln Lab succeeded in diode 
pumping a uranium-doped $\mathrm{CaF}_{2}$ laser, but only when it was cooled to $4 \mathrm{~K}$. Such experiments showed the potential of diode pumping, but diode laser technology was too immature for practical use.

Developers also tested a wide range of light-emitting ions, but like Sorokin and Stevenson's uranium- $\mathrm{CF}_{2}$ laser, most such laser candidates proved impractical because they suffered such serious limitations as low efficiency, poor absorption in the bands emitted by flashlamps, or the need for cryogenic operation. In a 1966 review in Applied Optics, Zoltan Kiss and Robert J. Pressley, then both at RCA Laboratories, tabulated an impressive list of solid state lasers that had been demonstrated in crystalline hosts. ${ }^{80}$ Most were based on trivalent rare earths such as neodymium, holmium, erbium, and ytterbium or the transition metals chromium, cobalt, and nickel. They observed the potential of "sensitized" systems, in which one element absorbs the pump band and transfers the excitation to a second element. But even at that early date they recognized Nd-YAG as "the best room temperature continuous system," and used it as a benchmark for evaluating solid state laser performance.

By 1969 , seven laser lines had been observed ${ }^{81}$ in glass doped with five different trivalent rare earths: neodymium at $0.92,1.06$, and $1.37 \mu \mathrm{m}$; erbium at $1.54 \mu \mathrm{m}$; holmium at $2.1 \mu \mathrm{m}$; thulium near $2 \mu \mathrm{m}$; and ytterbium near $1.06 \mu \mathrm{m}$. Glass could be made in a wide variety of compositions and geometries, from thin fibers to large slabs. Large rods and slabs could be used to amplify laser pulses, although the thermal conductivity of glass limited repetition rates.

The bottom line was that ruby, Nd-YAG, and Nd-glass lasers were the best solid state lasers available after a decade of development. Direct output at wavelengths shorter than ruby were elusive, but neodymium could be frequency doubled into the green.

\section{Diverse Application Requirements}

The first decade of laser development also saw the emergence of a range of applications that shaped the design and marketing of laser products tailored to the requirements of those applications.

One broad class of applications such as communications required little power because the beam's purpose was to transfer information. Communications required low-power continuous-wave lasers, which could be modulated to transmit signals. Diode lasers were generally considered the most promising type for communications, and Bell Labs had a major program in diode-laser development. However, Bell's optical communication program focused largely on hollow light pipes until 1970, despite Charles Kao's campaign for fiber-optic systems. ${ }^{82}$ For communications and other low-power information-related applicationsincluding surveying, measurement, and construction alignment-lasers were chosen because they delivered well-controlled photons.

Some measurement applications required pulsed beams, notably laser radars, rangefinders, and target designators, which measured distances to objects and "marked" potential targets for smart bombs. These applications had different requirements, such as short pulses that could accurately measure distances. Concern about the eye safety of laser beams used outdoors led to interest in lasers emitting at wavelengths beyond about $1.4 \mu \mathrm{m}$, which do not penetrate to the retina, such as erbium, holmium, and thulium.

Another class of applications used laser energy to modify what the beam illuminated, from exposing lightsensitive films to cutting and welding. These applications require a minimum power to cause the change, and a wavelength absorbed by the target. Often the beam must be controlled very precisely. This often led to collaborations. For example, Eugene Gordon and Ed Labuda of Bell Labs worked with Columbia-Presbyterian Hospital ophthalmologist Francis L'Esperance to develop argon laser systems that could destroy the abnormal blood vessels that cause blindness in diabetic retinopathy. ${ }^{83}$ Other examples are in materials working, where short pulses are required for hole drilling, and the choice of lasers depends on the material being processed. Lasers also needed to be built so they could be used by nonspecialists.

Military interest in laser weapons pushed developers to scale lasers to the highest possible powers. Early projects focused on solid state lasers, but glass or crystalline lasers shattered or cracked at high pulse energies, so in the mid1960s military researchers turned to developing high-power gas lasers after the $\mathrm{CO}_{2}$ laser scaled to a high power. However, solid state lasers remained in contention for highpower pulsed applications in laser fusion.

\section{Making Diode Lasers Practical}

Both the promise and problems of semiconductor diode lasers were evident from the first demonstrations. By the early 1960s it was clear that semiconductor devices were the future of electronics, so it seemed logical to expect them to be the future of laser communications. However, there were formidable problems to overcome in producing diode lasers that could operate at room temperature

Early diode lasers were broad-area devices with the same composition of GaAs or another III-V semiconductor on both sides of junction layer, called homojunction lasers. In 1963, Herbert Kroemer of the Varian Central Research Laboratory suggested adding a layer with different composition and bandgap to create a heterojunction that would trap electrons at the junction so they could more readily combine with holes and emit light. ${ }^{84}$ Zhores Alferov and Rudolf Kazarinov came up with the idea independently at the Ioffe Physics Institute and later made the first heterojunctions. $^{85}$ (A team at IBM was close behind, but their paper submitted a month after Alferov's appeared first in English. ${ }^{86}$ )

Jack Dyment of Bell Labs contributed a second key idea, limiting current flow and recombination to a narrow stripe in the junction layer. Although it did not reduce drive current as much as he had hoped, it significantly improved beam quality, which had been an issue. ${ }^{87}$

Both Alferov's group and Mort Panish and Izuo Hayashi at Bell Labs began developing double-heterojunction lasers without realizing they were in competition until August 1969, when Alferov made his first visit to the United States Both redoubled their efforts to beat the competition. Alferov (shown in Fig. 12 with a colleague), added a narrow stripe to his design, and was the first to show continuous room-temperature operation, although the news took months to reach the United States. ${ }^{88}$ Panish and Hayashi ${ }^{89}$ achieved cw room-temperature operation a few weeks later 


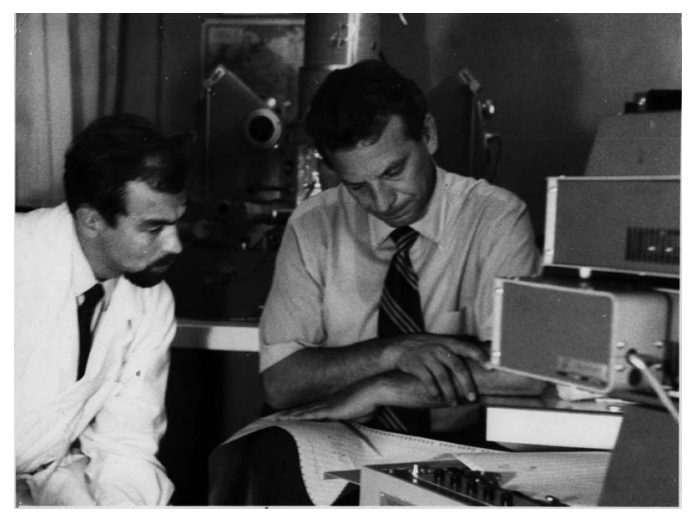

Fig. 12 Zhores Alferov (right) and a colleague at the loffe Physics Institute, where they developed double-heterostructure diode lasers. (Courtesy Zhores Alferov)

in a diode without a narrow stripe, which Hiyashi shows in Fig. 13. Alferov shared the 2000 Nobel prize for the heterojunction with Kroemer.

The first cw diode lasers operated only seconds to hours at room temperature. Bell Labs took the lead in extending lifetime to meet telecommunication system requirements. After seven years of effort, and exhaustive accelerated aging tests, Robert L. Hartman, Norman E. Schumaker, and Richard Dixon ${ }^{90}$ reported making GaAlAs lasers with mean time to failure of more than 100 years.

Ironically, by the time Bell pushed GaAs lasers to that impressive lifetime, the long-wavelength fiber-optic transmission window at 1.3 to $1.55 \mu \mathrm{m}$ had been opened, and $\mathrm{J}$. Jim Hsieh and C. C. Shen ${ }^{91}$ had already demonstrated room-temperature operation of InGaAsP lasers at $1.25 \mu \mathrm{m}$. Although GaAs lasers found few uses in long-distance telecommunications, Bell's work made it easier to improve InGaAsP lasers, and made long-lived GaAs lasers available for other mass-market applications such as CD players and laser printers.

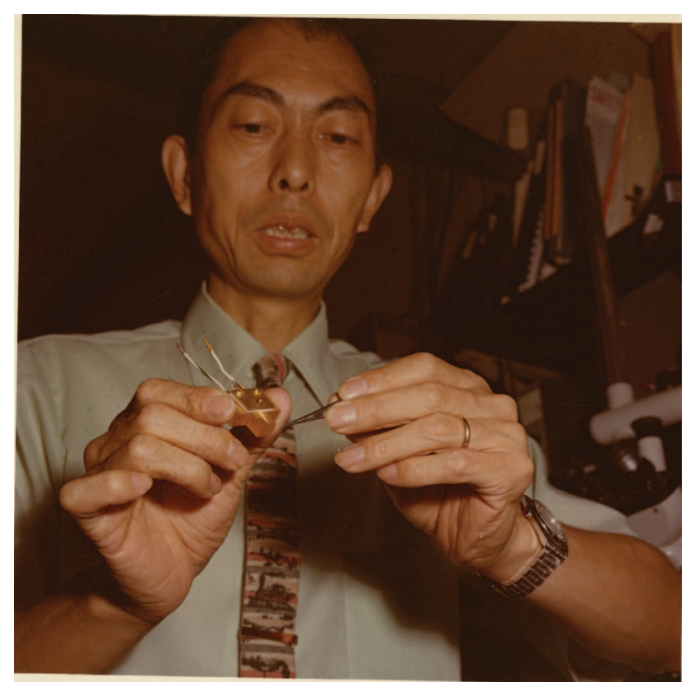

Fig. 13 Izuo Hayashi holds his first room-temperature cw diode laser. (Courtesy of Bell Labs)

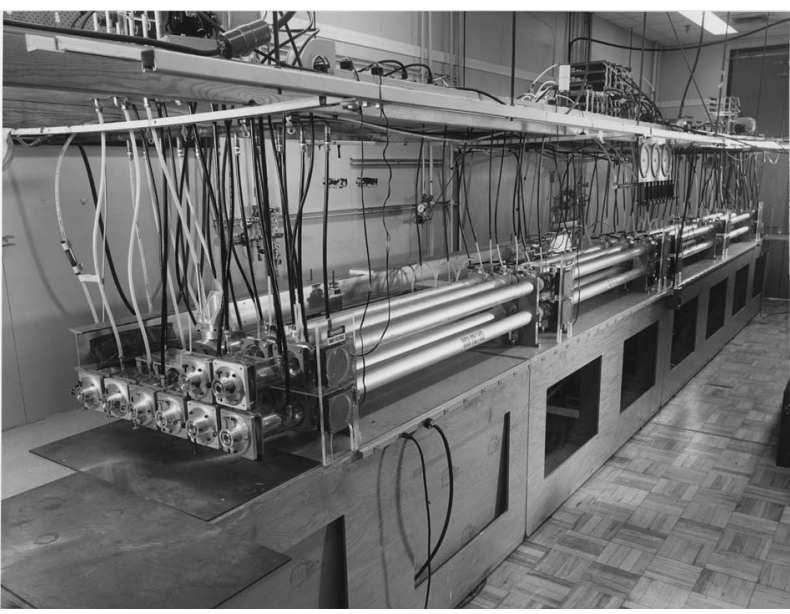

Fig. 14 To generate $1.5 \mathrm{~kW}$ in the late 1960s, Hughes Research Laboratories passed the output of a $10-\mathrm{m} \mathrm{CO}_{2}$ oscillator through a 12-m preamplifier and a 42-m amplifier. The tubes were folded to fit onto a 32- $\times 4$-ft plywood table. (Courtesy W. Bridges)

\section{High-Energy Gas Lasers}

Early efforts by military contractors to scale $\mathrm{CO}_{2}$ lasers succeeded in reaching kilowatt powers at the cost of enormous sizes. Figure 14 shows one example, a $1.5-\mathrm{kW}$ laser that Hughes Research Labs built in the late 1960s. Output of a $10-\mathrm{m}$ oscillator was amplified by passing it through a $12-\mathrm{m}$ preamplifier in a $25-\mathrm{mm}$ tube and a $42-\mathrm{m}$ amplifier in a $50-\mathrm{mm}$ tube. The tubes were folded to fit onto a 32- $\times 4$-ft plywood table. ${ }^{92}$ Hughes later reinstalled it in a much neater-but equally massive-form at the Rome Air Development Center radar site.

Trying to find ways to build a far more powerful laser, Edward Gerry and Arthur Kantrowitz at the Avco Everett Research Laboratory realized that a rocket engine could generate a gigawatt, so extracting only $0.1 \%$ of that power could yield a megawatt beam. Their gasdynamic laser burned a carbon-rich fuel in oxygen, and expanded the $\mathrm{CO}_{2}$-rich combustion products into a low-pressure laser cavity to produce a population inversion in the flowing gas. They reached $50 \mathrm{~kW}$ in 1966, but their results were classified $^{93}$ until 1970. By that time, gas-dynamic laser powers had exceeded $100 \mathrm{~kW}$, and the Airborne Laser Laboratory built in the $1970 \mathrm{~s}$ eventually reached a reported $400 \mathrm{~kW}$. However, the $10-\mu \mathrm{m}$ beam required unacceptably large optics to control beam divergence, atmospheric transmission was problematic, and the laser itself was so massive and so complex that cynics called it a "ten-ton watch."

Military developers succeeded in scaling hydrogenfluoride chemical lasers to much higher powers, but poor atmospheric transmission in the 2.6- to $3-\mu \mathrm{m}$ band emitted by HF lasers forced the use of deuterium to shift wavelength to the more transparent band of 3.6 to $4 \mu \mathrm{m}$ for ground-based operation. The Navy's DF Mid-InfraRed Advanced Chemical Laser (MIRACL) and DARPA's HF Alpha laser both reached megawatt class powers. Figure 15 shows the now-dismantled test site for Alpha, a cylindrical laser intended to show the feasibility of operating a highenergy chemical laser in space; note the car at the lower left that shows its scale. 


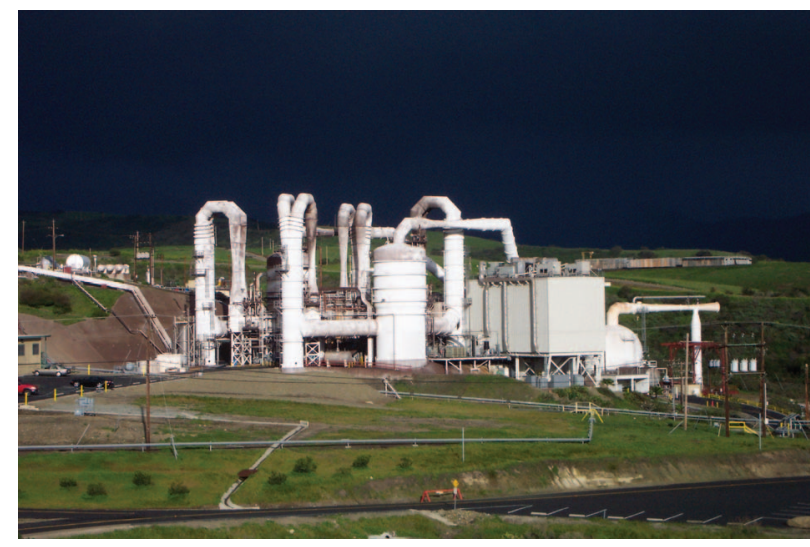

Fig. 15 DARPA built the megawatt-class Alpha HF chemical laser during the 1980s to test prospects for an orbiting chemical laser battle station. Its ability to operate in vacuum was tested in this dedicated facility built by TRW, now part of Northrop Grumman. For scale, note the car at lower left and the sawhorse in lower center. (Courtesy of Northrop Grumman)

Starting in the 1970s, DARPA and other military agencies pushed development of shorter-wavelength lasers, seeking higher efficiency, smaller optics and better transfer of laser energy to targets. Projects including visible chemical lasers, ultraviolet lasers, and x-ray lasers. So far, the only other laser to reach megawatt-class powers continuous-wave is the $1.3-\mu \mathrm{m}$ chemical oxygen-iodine laser (COIL) used in the Air Force's Airborne Laser. ${ }^{94}$ However, military interest in short wavelengths contributed to early development of excimer and free-electron lasers.

\section{Excimer Lasers}

F. G. Houtermans ${ }^{95}$ proposed that laser action might be possible excited dimers (often shortened to excimers) of mercury $\left(\mathrm{Hg}_{2}^{*}\right)$ in 1960 , but it wasn't until 1970 that Nikolai Basov and colleagues demonstrated gain at $175 \mathrm{~nm}$ in the vacuum uv from dimers formed by electron-beam pumping of liquid xenon. ${ }^{96}$ Two years later a Livermore group observed gas-phase lasing from $e$-beam pumped $\mathrm{Xe}_{2}^{*}$ at $171.6 \mathrm{~nm}$ at elevated gas pressures. ${ }^{97}$ Krypton and argon dimer lasers followed. These dimers are unstable in their ground state, so laser transitions dropping to that state should have virtually zero lower level population, making them attractive for high powers. However, pure noble-gas dimers did not live up to that expectation. ${ }^{98}$

Donald W. Setser and J. E. Velazco of Kansas State University then reported that diatomic molecules containing a rare gas atom and a halogen behaved similarly. ${ }^{99}$ They suggested rare-gas halides would make good lasers, but lacked the equipment to test their idea. (Strictly speaking the raregas halides are not true dimers because the two atoms are not identical, but they were nonetheless called "excimers.")

Stuart Searles and G. A. Hart did have the needed equipment because they had been studying $\mathrm{Xe}_{2}^{*}$ lasers at the Naval Research Laboratory. They added a dash of bromine to the xenon in the laser chamber, changed mirrors, and fired their electron beam into the mixture, producing ${ }^{100} 282-\mathrm{nm}$ laser emission from $\mathrm{XeBr}$. They disclosed their results at a NRL seminar, ${ }^{101}$ and several attendees quickly made other rare-gas halide lasers in impressive burst of invention. J. J.

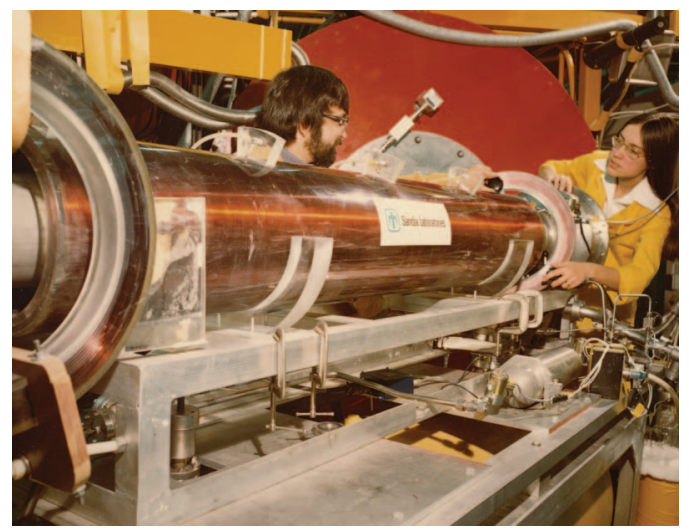

Fig. 16 Gary Tisone (left) and A. Kay Hays (right) set up an electron-beam pumped ArF laser experiment at Sandia National Laboratories. (Courtesy Sandia National Labs)

Ewing and Charles Brau at Avco Everett quickly reported three other rare-gas-halide lasers, $\mathrm{KrF}$ at $259 \mathrm{~nm}, \mathrm{XeCl}$ at $308 \mathrm{~nm}$, and $\mathrm{XeF}$ at $354 \mathrm{~nm}$, which they reported in Applied Physics Letters shortly after the NRL XeBr laser. ${ }^{102}$ Mani Bhaumik and Earl Ault at the Northrop Research and Technology Center reported an $\mathrm{XeF}$ excimer at the same time. ${ }^{103}$ Electron-beam pumping of KrF by Gary Tisone, A. Kay Hays, and J. M. Hoffman at Sandia National Labs produced 100-MW pulses with up to $3 \%$ efficiency. ${ }^{104}$

The first round of experiments all used electron-beam pumping. Ralph Burnham, N. W. Harris, and Nicholas Djeu at NRL succeeded in pumping $\mathrm{XeF}$ with a pulsed transverse discharge in early September 1974, and reported the results just a week later at a meeting on electronic-transition lasers in Woods Hole, Massachusetts. ${ }^{105}$ The following year, Hoffman, Hays, and Tisone ${ }^{106}$ made the first argon fluoride laser emitting at $193 \mathrm{~nm}$. Figure 16 shows Tisone and Hays setting up an $e$-beam ArF experiment. Pulsed high-voltage discharges soon replaced $e$-beam excitation for all but the highest power rare-gas halide lasers.

The rare-gas halides were not the first uv lasers, but they were by far the most powerful. Molecular nitrogen lasers emitting at $337 \mathrm{~nm}$ were discovered in 1963 by H. G. Heard, ${ }^{107}$ and were widely used in research and pumping dye lasers. They were so easy to make that Scientific American published instructions for amateur scientists. ${ }^{108}$ However, their modest pulse energies and low repetition rates limited their applications. Doubly ionized argon, krypton, and cadmium emit $\mathrm{cw}$ in the ultraviolet, but their powers and efficiencies are low, limiting their applications.

In time, rare-gas halide lasers found major applications in both industry and medicine. ${ }^{109} \mathrm{KrF}$ lasers, the most powerful type, were the first lasers used in semiconductor photolithography. As resolution requirements increased, they were replaced by ArF lasers, which remain standard for making integrated circuits with only a small fraction of their 193-nm wavelength. ArF lasers also are standard for refractive surgery because their short wavelength is most effective for ablating tissue. 


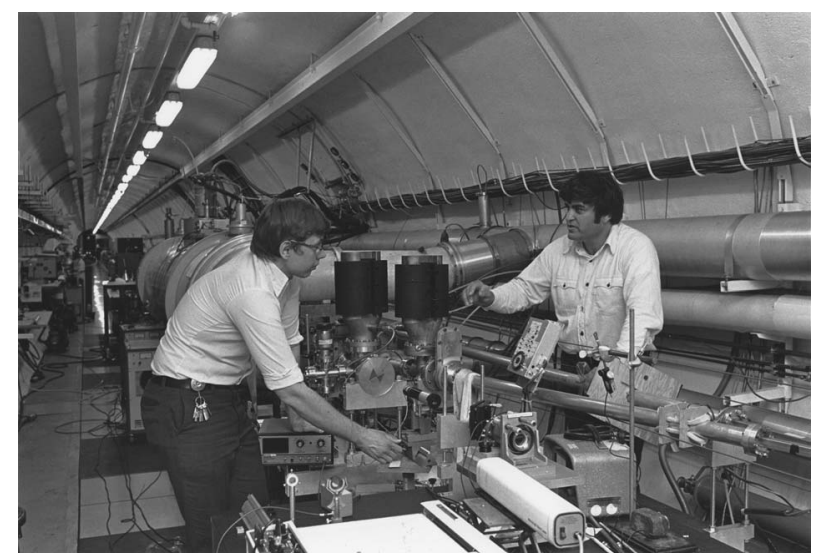

Fig. 17 John M. J. Madey (left) and Luis Elias (right) work on an early free-electron laser experiment at Stanford. (Courtesy of Stanford University)

\section{Free-Electron Lasers}

The free-electron laser was one of the more unusual ideas to emerge in the 1970s. In 1971, John M. J. Madey proposed extracting energy from a beam of high-energy electrons by bending their paths back and forth as they passed through an array of magnets with alternating polarity. ${ }^{110}$ (Similar devices had been operated earlier at microwave frequencies, but as with lasers and microwave masers, there were appreciable differences in the two regimes.)

Madey and colleagues spent the next several years developing the concept. In 1976 they observed stimulated emission in the infrared at Stanford. ${ }^{111}$ The following year they observed ${ }^{112}$ laser oscillation, also in the IR. Figure 17 shows Madey and Luis Elias working on an early freeelectron laser experiment.

In principle, a free-electron laser could generate a powerful laser beam, and use of a storage ring could improve efficiency by recycling the electrons repeatedly through the wiggler. Moreover, the wavelength depends on the electron energy and the magnet spacing, so tunability is possible, and the principle can be applied from microwaves to $\mathrm{x}$ rays, although in practice the range of any single free-electron laser is limited. However, those attractions were offset by the need for a powerful electron accelerator, and progress was slow.

\section{Lasers for Research Applications}

Laser spectroscopy blossomed in the 1970s with the spread of tunable dye lasers and the development of powerful new spectroscopic techniques. Lasers offered important advantages over conventional spectroscopic sources, including narrow linewidth and concentrating a very high power in a narrow band, making more photons available for measurements. But those features were of limited value until tunable lasers made lasers available across the optical spectrum rather than only in a few narrow bands. Not only did individual dyes have broad emission bandwidth, but there were many dyes available, so together they spanned the optical range.

Tunable dye lasers greatly extended the power of techniques originally demonstrated with fixed-wavelength lasers. Robert Terhune first demonstrated coherent anti-
Stokes Raman spectroscopy (CARS) with a ruby laser in 1965 at the Ford Motor Company. ${ }^{113}$ A decade later, tunable dye lasers made CARS a powerful and broadly applicable technique. ${ }^{114}$ Tunable dye lasers also led to completely new techniques, such as two-photon doppler-free spectroscopy, developed independently in 1974 by David Pritchard, J. Apt, and $\mathrm{T}_{\mathrm{i}} \mathrm{W}$. Ducas at the Massachusetts Institute of Technology ${ }^{115}$ (MIT) and Theodor Hänsch et al. at Stanford. ${ }^{116}$ The rapid growth of such techniques stimulated the growth of laser technology, but the details are beyond the scope of this article.

Laser spectroscopy was not entirely pure research. In the mid-1970s, the United States and Soviet Union began investigating the use of lasers in isotope enrichment. One goal was selective excitation of uranium-235 to enrich concentration of the isotope for reactor fuel. The U.S. Department of Energy also conducted a classified program to purify plutonium for use in nuclear weapons by removing plutonium-240, which releases undesired neutrons by spontaneous fission. Developers hoped that laser enrichment would be far more efficient-and much less energy intensive- than the gaseous diffusion process then used to produce U.S. reactor fuel. The isotope enrichment programs sponsored development of copper-vapor pumped dye lasers to selectively excite isotopes in metal vapors, and infrared and ultraviolet lasers for a two-stage process to selectively excite and collect $\mathrm{UF}_{6}$ molecules containing $\mathrm{U}-235$.

Inertial-confinement fusion also became a large research program in the $1970 \mathrm{~s}$, aimed largely at simulating nuclearweapon physics on a laboratory scale, with a long-term goal of research on civilian fusion reactors. This required high-energy nanosecond-scale laser pulses to heat and compress targets. Carbon dioxide lasers were studied briefly at Los Alamos, and the Naval Research Laboratory built massive rare-gas-halide lasers, but most fusion lasers were lamp-pumped neodymium lasers, which in recent years have been put through a third-harmonic generator to produce uv pulses.

\section{Ultrafast Research and Broadband Lasers}

The broad spectral bandwidth of dyes opened the door to ultrafast pulse generation as well as tunability. In 1964, Willis Lamb showed that modelocking a laser could generate pulses limited in duration by the Fourier transform of the bandwidth. ${ }^{117}$ By passively modelocking the output of a cw dye laser, Erich Ippen and Charles Shank first generated 1.5 -ps pulses, ${ }^{118}$ and later produced subpicosecond pulses with kilowatt peak power. ${ }^{119}$ This led to a long series of experiments in generating shorter pulses by combining pulse compression and spectral broadening of laser pulses, culminating in 1987 when Richard Fork's group at Bell Labs generated 6-fs pulses by a combination of pulse compression and phase compensation. ${ }^{120}$

Dye lasers did have important limitations, particularly in being cumbersome to use, so developers looked for broadly tunable alternatives. This led to interest in solid state lasers with vibronic transitions, in which electronic transitions strongly interact with atomic vibrations, so the resulting vibronic transition has gain across a range of wavelengths. Leo Johnson et al. ${ }^{121}$ at Bell Labs demonstrated the first 


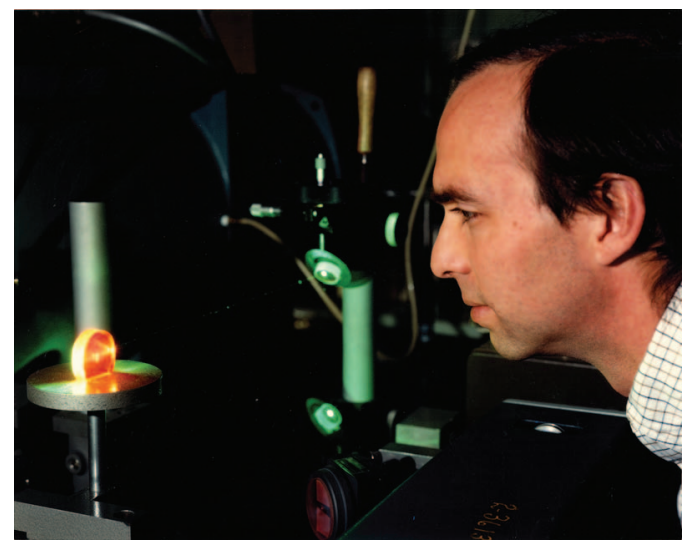

Fig. 18 Peter Moulton with an early Ti-sapphire crystal at MIT Lincoln Laboratory. (Courtesy of Peter Moulton)

vibronic laser, nickel-doped $\mathrm{MgF}_{2}$, in 1963, but it required cryogenic cooling and was of no practical interest. In the late 1970s, John Walling and colleagues at Allied Corp. found that laser emission from cobalt-doped alexandrite $\left(\mathrm{BeAl}_{2} \mathrm{O}_{4}\right)$ was broadly tunable. ${ }^{122}$ Early alexandrite lasers operated pulsed or $\mathrm{cw}$ with lamp pumping, and tuning range 700 to $800 \mathrm{~nm}$.

The most important tunable solid state laser, titaniumdoped sapphire $\left(\mathrm{Al}_{2} \mathrm{O}_{3}\right)$ was pioneered by Peter Moulton at the MIT Lincoln Laboratory (shown in Fig. 18 with an early Ti-sapphire crystal). ${ }^{123}$ Ti-sapphire had a much broader tuning range, 660 to $1180 \mathrm{~nm}$, but required laser pumping, initially with an argon-ion laser and later with a frequency-doubled neodymium laser. Commercial versions came on the market in late 1988 and started to replace dye lasers in spectroscopy.

A big boost to producing short pulses came from the development in 1990 of what is now called Kerr-lens mode-locking, in which self-focusing within the Tisapphire crystal causes bunching of a mode-locked pulse circulating within the laser cavity. Previously, producing pulses much shorter than 100 fs was an extremely complex and cumbersome process, limiting the process to a few laboratories. The new technique, developed by D. E. Spence, P. N. Kean, and Wilson Sibbett ${ }^{124}$ of the University of St. Andrews, allowed a self-mode-locked Ti-sapphire laser to generate pulses as short as $60 \mathrm{fs}$. Adding an intracavity pulse compressor reduced pulse duration to $45 \mathrm{fs}$. Crucially, the new approach was much easier to use than previous ultrafast lasers, and Ti-sapphire became the laser of choice for generating femtosecond pulses.

Dramatic reductions in Ti-sapphire pulse duration followed, and the solid state system started crowding dye lasers out of high-performance ultrafast research. By 1995, the record pulse length was reduced to $8 \mathrm{fs}$ by using chirped dielectric mirrors. ${ }^{125}$ In 2001, a team from labs in Germany, the United States, and Australia generated 5-fs pulses, which spanned an octave in wavelength from 600 to $1200 \mathrm{~nm}$, by adding double-chirped mirror pairs for broadband dispersion control and added a second focus in an intracavity glass plate to enhance spectral broadening. The system set records for the broadest bandwidth and shortest pulses from a laser oscillator; only the shorter pulses had required external compression. ${ }^{126}$

The emergence of ultrafast pulses opened the way to new types of spectroscopy. Winifred Denk, J. H. Strickler, and Watt Webb focused femtosecond red or IR pulses to high enough intensity that a sample could absorb two or more photons simultaneously to excite fluorescence, but only during the brief peak intensity of the pulse. ${ }^{127}$ As in confocal microscopy, the sharp focus reduces noise from areas in front or in back of the target material.

\section{From Consumer Products to "Star Wars"}

The 1980s saw lasers emerge much more into the public eye both as integral parts of the consumer economy, and as a potential defense against nuclear attack.

Development of mass-produced laser-based products began in the early 1970s using red helium-neon lasers. The first to reach the market was the laser supermarket scanner, which began its first field trial at a Marsh supermarket in Troy, Ohio, in 1974. Adoption was initially slow, and the systems had to be designed to keep the scanning beam away from customers so checkout counters didn't need safety warning labels, but by the early 1980s supermarket scanners were commonplace.

The next big products were optical disks. MCA and Phillips spent years developing the LaserVision videodisk player, which used helium-neon lasers to play $60 \mathrm{~min}$ of video per side from $30-\mathrm{cm}$ disks. Small-scale testmarketing began in Atlanta, Georgia, in December 1978, but the player wasn't broadly available until a couple of years later. By then, it faced competition from RCA's capacitive SelectaVision videodisk. RCA invested heavily in promotion, but the public preferred video cassette recorders and RCA lost hundreds of millions of dollars before stopping production in April 1984 after barely three years on the market. ${ }^{128}$ Although never more than a niche market, $30-\mathrm{cm}$ laser disks survived for decades. Pioneer said that some 16.8 million players had been sold worldwide when it finally stopped producing ${ }^{129}$ its LaserDisc players in January 2009.

The real success of optical disks was the $12-\mathrm{cm}$ audio compact disc, played by $780-\mathrm{nm}$ GaAlAs laser. Initially introduced in Japan in 1982, they sold in the United States for about $\$ 1000$ the following year. Affluent audiophiles loved them, and as sales increased, prices dropped until CDs became the standard medium for music, and CD players brought lasers into most households in developed countries.

President Ronald Reagan brought lasers into a different public spotlight with his March 23, 1983, "Star Wars" speech. The Strategic Defense Initiative (SDI) envisioned building orbital chemical laser battle stations to defend against nuclear attack. The idea wasn't new, and DARPA already was trying to develop the technology, but SDI put laser weapons in the spotlight, and Congress poured money into the program. It was a mixed blessing for the laser community. SDI's fire-hose of massive funding focused only briefly, peaking around $\$ 1$ billion a year in the mid1980s. However, funding for laser research dropped after delays and serious technical problems with laser weapon projects. $^{130}$ 


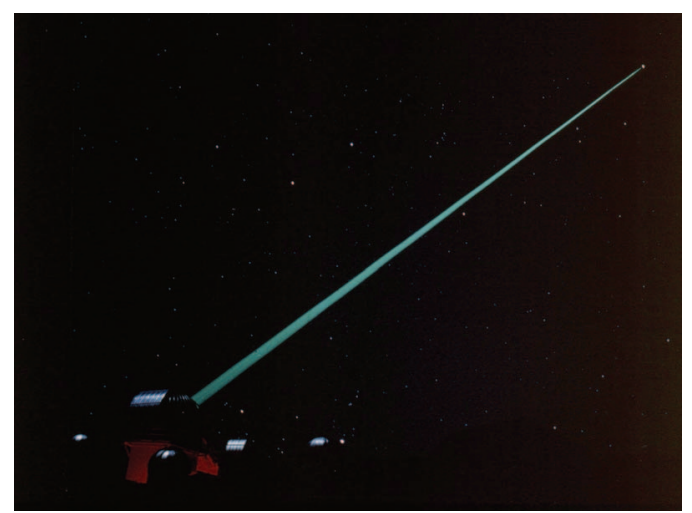

Fig. 19 Copper vapor laser used as a laser guide star with a 1.5-m telescope at the Air Force Starfire test range in New Mexico. (Courtesy of Colin Webb)

Although Star Wars programs aimed at building megawatt-class lasers made only modest contributions to the long-term development of laser technology, the adaptive optics technology developed to get high-power beams through the atmosphere is now widely used in largeaperture ground-based telescopes. Figure 19 shows a copper-vapor laser guide star system being tested with a 1.5-m telescope at the Air Force Starfire test range in New Mexico. A series of tests showed the guide-star system could improve image quality, ${ }^{131}$ and similar systems based on solid state lasers are now used on many large telescopes.

The most important contribution Star Wars made to laser technology was on a smaller scale, supporting the development of high-power diode lasers.

\section{Higher Power and Shorter Wavelength Diodes}

Like early transistors, early diode lasers were fabricated on semiconductor wafers then sliced and diced into tiny chips that were packaged individually. The first commercial $\mathrm{cw}$ diode lasers, introduced in the mid-1970s, were stripegeometry double-heterostructure lasers that emitted a few milliwatts. Powers crept steadily upward, but the output from a single stripe was inherently limited, so developers seeking higher powers turned to wide-stripe lasers and to multistripe arrays.

The idea of assembling diode lasers in stacks or arrays originated in the days of pulsed single-heterojunction lasers used for some military applications in the 1970s. In 1978, Donald Scifres, R. D. Burnham, and William Streifer ${ }^{132}$ at the Xerox Palo Alto Research Center fabricated a monolithic a phase-locked array of five optically coupled doubleheterostructure laser stripes, generating total output of more than $100 \mathrm{~mW}$ per facet. Spectra Diode Laboratories, headed by Scifres, later commercialized the diode arrays. In 1985 , the company introduced a monolithic array of $10 \mathrm{cw}$ GaAlAs diode-laser stripes emitting $200 \mathrm{~mW}$, that Lasers \& Applications rated as one of the year's top products. ${ }^{133}$ Laboratory powers were considerably higher. In 1986, Spectra Diode reported 4-W cw output from an array of 140 stripe lasers on a 1-mm bar. ${ }^{134}$ By 1989, Spectra Diode had cranked up the power by more than a factor of 10 , producing $76-\mathrm{W} \mathrm{cw}$ from a $1-\mathrm{cm}$ array with $30 \%$ packing density before it failed. ${ }^{135}$ Operating at $7 \mathrm{~W}$, the arrays could last for more than $3000 \mathrm{~h}$.

The higher powers came at a cost in beam quality, but that wasn't a big issue for diode pumping of solid state lasers. Nd-YAG was a logical choice for diode pumping because of its strong pump line at $808 \mathrm{~nm}$, easily generated by GaAlAs, and the first commercial diode-pumped lasers were introduced $^{136}$ in 1984 , emitting $100 \mathrm{~mW} \mathrm{cw}$. Diode pumping was far more efficient than lamp pumping, and efficiently converted multimode diode output into a higher quality single-mode beam. Nd-YAG also stored energy well, so Q-switching could generate high peak powers. As pump diode powers increased, so did the diode-pumped output. In 1987, Laser Diode Products of Earth City, Missouri, introduced a $1-\mathrm{W}$ cw diode-pumped Nd-YAG laser. $^{137}$

Powers weren't all that were improving. The lifetime and performance of GaAlAs diode lasers dropped sharply below the 780-nm wavelength used in CD players, and offered little hope for output shorter than $700 \mathrm{~nm}$. In 1985, Sony researchers reported cracking that barrier by developing $\mathrm{AlGaInP}$ diodes emitting $\mathrm{cw}$ at room temperature at $671 \mathrm{~nm}$ in the laboratory. ${ }^{138}$ Two years later, Tohru Suzuki of NEC told CLEO 1987 that GaInP diode lasers had operated at 3 to $5 \mathrm{~mW}$ at $678 \mathrm{~nm}$ for more than $4500 \mathrm{~h}$ at room temperature, doubling the operating time reported earlier in the year, ${ }^{139}$ and highlighting his talk with a red diode pointer build from one of the lasers.

But the most stunning news on the short-wavelength laser frontier didn't come until the 1990s. I got a preview in 1991, when Isamu Akasaki of Nagoya University showed me a battery-powered blue gallium-nitride LED in a laserpointer-sized package in the press room at the Materials Research Society fall meeting in Boston; he had first made blue LEDs two years earlier. ${ }^{140}$ After years of development, GaN was being tamed for LEDs and lasers. ${ }^{141}$ However, the conventional wisdom remained that the best hope for shortwavelength diode lasers were II-VI compounds such as $\mathrm{ZnSe}$, which could emit pulses at room temperature around $500 \mathrm{~nm}$.

In 1994, a small company called Nichia Chemical announced it could make blue LEDs with $2 \%$ electrical to optical conversion efficiency at $450 \mathrm{~nm}$, but it was only an LED, and nitrides still had a reputation of being difficult materials. In 1996, Shuji Nakamura et al. reported ${ }^{142}$ fabricating the first $\mathrm{cw}$ blue/violet laser, from InGaN. He has been widely honored for his success with a material others had not thought could work. ${ }^{143}$

\section{Fiber Amplifiers and Lasers}

Another revolution was also in progress. More than two decades after Elias Snitzer had first demonstrated fiber lasers-and a fiber amplifier as well ${ }^{144}$ - that technology finally came into its own.

In 1985, after fabricating a series of special-purpose optical fibers at the University of Southampton, David Payne decided to try doping fiber cores with rare-earth elements to make fiber lasers. He started with neodymium, and after measuring low attenuation in the fiber, tried pumping the fiber with a GaAs laser. It took less than $1 \mathrm{~mW}$ from the pump to reach laser threshold. ${ }^{145}$ He tested other rare-earth elements, and found that the neodymium laser could be 
tuned across $80 \mathrm{~nm}$ and the erbium-fiber laser, pumped at different wavelengths, could be tuned ${ }^{146}$ across $25 \mathrm{~nm}$ near $1535 \mathrm{~nm}$.

Payne's group played with fiber lasers extensively before thinking seriously about amplifiers. "It took us 26 publications on fiber lasers before we realized that if we took the mirrors off and looked at what the gain was ... we'd have a huge gain of $30 \mathrm{~dB}$," Payne told me for a 2002 article. ${ }^{147}$ In early 1987 , he reported gain of $26 \mathrm{~dB}$ at $1536 \mathrm{~nm}$ when pumping an erbium-doped fiber with the $514.5-\mathrm{nm}$ line of an argon-ion laser. ${ }^{148}$ That gain falls close to the minimum of optical-fiber attenuation.

Developers of single-mode fiber-optic systems originally picked $1310 \mathrm{~nm}$ for signal transmission because that is the zero-dispersion wavelength of step-index single-mode fibers. But they also wanted all-optical amplifiers to replace the electro-optic regenerators that had been installed about every $50 \mathrm{~km}$ in first-generation single-mode fiber systems. With serious money invested in 1310-nm systems, fiberoptic developers would have preferred amplifiers for that wavelength.

Erbium proved much better. Emmanuel Desurvire of Bell Labs characterized erbium amplification in detail, so engineers could design practical amplifiers. ${ }^{149}$ Payne's group found that $980 \mathrm{~nm}$ was a good pump wavelength, ${ }^{150}$ and several other groups confirmed their findings. Snitzer analyzed the system and found that $1480 \mathrm{~nm}$ would also be a good pump wavelength. ${ }^{151}$ Diode lasers were developed for both pump bands. Field trials followed, and further experiments showed the erbium amplifier had the combination of broad bandwidth and low crosstalk needed for wavelength-division multiplexing. ${ }^{152}$ That helped launch the fiber-optic boom of the 1990s, described in the following.

Meanwhile, David Hanna of Southampton found that ytterbium was a particularly attractive ion for use in fiber lasers. Lasing in ytterbium was first observed ${ }^{153}$ in 1962 , but it had not looked promising as a laser material at the time because it lacked a true four-level transition. However, fiber laser experiments in the early 1990s showed that ytterbium worked very well as a laser in a fiber configuration, where longitudinal pumping concentrated pump energy to produce a strong population inversion. Moreover, pumping with InGaAs lasers emitting around $950 \mathrm{~nm}$ excited ytterbium efficiently, and with a much smaller photon defect than neodymium lasers. ${ }^{154}$

As Hanna's group predicted, ytterbium has become the active element of choice for fiber lasers. Indeed, ytterbiumdoped fiber lasers have done far better than anyone would have dared hope. The small photon-energy defect of ytterbium and the high efficiency of diode pumping combine with the energy-dissipation advantages of a fiber geometry to make fiber lasers very attractive for high-power applications. In 2009, IPG Photonics reported continuous output of $10 \mathrm{~kW}$ from a single-mode Yb-fiber oscillator-amplifier, and $50 \mathrm{~kW}$ in multimode fiber lasers. ${ }^{155}$ Those powers have led to military interest in fiber lasers for weapon applications.

\section{The Fiber-Optic Boom and Bust}

The rapid growth of the Internet and the development of the World Wide Web pumped up the demand for data transmis- sion in the 1990s. The explosive growth of fiber optics met that demand by multiplying the transmission capacity of the global telecommunications network at a rate even faster than the growth of Internet data traffic, but the mismatch went largely unnoticed. Indeed, even after the first wave of "dot coms" failed in 2000, the market for telecommunications equipment seemed strong. "Unlike the concept of selling dog food over the internet, telecomm isn't going away," said market analyst John Ryan in early 2002 . $^{156}$

Ryan was both right and wrong. The global network did need more capacity, but carriers overbuilt during the bubble, leaving excess long-haul and international capacity that took years to work off. Investors who had been throwing money at any optical technology wound up with an immense headache, but the money did spur development of laser technology. Pump diodes, fiber amplifiers, and fiber lasers all benefitted from large investments. The big new developments were in diode lasers.

High-speed telecommunications required the narrow linewidth and stable output wavelength offered by diode lasers fabricated with distributed feedback or distributed Bragg reflection gratings. Distributed feedback (DFB) diode lasers were first demonstrated ${ }^{157}$ in GaAs during the mid-1970s. Distributed Bragg reflector lasers followed, and development shifted to InGaAsP materials as developers moved to the 1.31 - and $1.55-\mu \mathrm{m}$ windows. In the early 1980s, developers achieved room-temperature operation and stable single-mode operation under high-speed direct modulation, as required for single-mode communication systems. ${ }^{158}$ That technology was steadily improved during the $1980 \mathrm{~s}$, as data rates rose from $400 \mathrm{Mbits} / \mathrm{s}$ to $2.5 \mathrm{Gbits} / \mathrm{s}$, and further refined for operation at $10 \mathrm{Gbits} / \mathrm{s}$ in wavelength-division multiplexing (WDM) systems during the 1990s.

The installation of WDM systems created a demand for tunable diode laser transmitters. Telecommunications carriers and system makers did not want to stock separate lasers for each optical channel; they wanted lasers that could emit at any wavelength they needed. Development of tunable diode lasers became a major research thrust in the late 1990s. One early approach was the external cavity laser, with an adjustable mirror outside the semiconductor chip moving to select a particular wavelength in a relatively broad band. ${ }^{159}$ The approach that proved more successful in the long term was monolithic integration of a laser with a pair of distributed Bragg reflector (DBR) gratings, which could be adjusted to tune wavelength resonant in the cavity. ${ }^{160}$ Ironically, that technology was not widely adopted in telecommunication systems until after the bubble collapsed.

Conventional diode lasers oscillate in the plane of the $p$ - $n$ junction, with cleaved facets on the edges of the chip, but over the years researchers have studied many alternatives. The most successful of these is the vertical cavity surface-emitting laser (VCSEL), first operated at room temperature by Kenichi Iga et al. ${ }^{161}$ in 1985 . In their original laser, light emerged from a hole etched through the substrate to the bottom $n$-doped layer, with the surface coated with a partially reflective gold layer. The top $p$ layer and electrical contact were also coated with a reflective layer as 
the rear cavity mirror. The DBR mirrors now used to form the VCSEL cavity were developed later by Larry Coldren and colleagues. ${ }^{162}$

VCSEL operation differs in important ways from that of edge-emitting diodes. The cavity is extremely short but the emitting area is wide, so VCSEL beams are more circular and less divergent. VCSELs have a low threshold current, but the small active volume limits output power, and limits their use in communications to short-distance transmission. However, VCSELs have a crucial advantage in the practical matter of manufacture-they can be tested on the wafer, before cutting the semiconductor into individual chips, greatly reducing packaging costs. This has gained VCSELs wide use in low-power diode applications.

The bubble pumped funding into other interesting optical technologies that might have otherwise received little funding, such as quantum cryptography, which relies on the quantum mechanics to ensure security. Because secure quantum data transmission is slow, a secure quantum link is used only to transmit a secure key that could be used to decode a encoded public data transmission. A few companies have offered commercial systems, but quantum cryptography is still in a state of intense research, and has some special requirements for optical sources. ${ }^{163}$

\section{The Solid State Laser Revolution}

The postbubble era has seen a solid state revolution reshaping the laser world. A few gas lasers have reasonably secure niches. $\mathrm{CO}_{2}$ and ArF, with high efficiencies at wavelengths not readily available at comparable powers from solid state lasers, may be the more important examples. But new and improved solid state lasers (including fiber and semiconductor types) are pushing into other niches long occupied by gas lasers.

High-power diode lasers are a major driving force. They can convert more than half of the input electrical power to light, a remarkable efficiency for any light source. Modulating the drive current directly modulates the laser output, simplifying many operations. Diode beams can directly perform many applications that don't require high beam quality, such as heat treating or soldering. If better beam quality is necessary or other wavelengths are required, diodes can pump fiber or solid state lasers.

The high efficiency of diode pumping changes the rules for other solid state lasers. Pumping with lamps or other lasers is inherently inefficient. Lamps convert only a fraction of input energy into pump light, only a fraction of the lamp output is absorbed by the laser rod, and only part of the absorbed energy winds up in the laser beam. Twenty years ago, Walter Koechner wrote that about $2 \%$ of the input energy wound up in the beam of a well-designed lamp-pumped laser. ${ }^{164}$ The remaining $98 \%$ of the energy was dissipated as heat, so a $20-\mathrm{W}$ laser would require $1 \mathrm{~kW}$ of electrical power and dissipate $980 \mathrm{~W}$ of heat.

In contrast, in diode-pumped lasers, typically half the electrical power becomes pump light and half the pump light is converted into solid state output beam, for $25 \%$ wall-plug efficiency. Instead of requiring $980 \mathrm{~W}$ of input power, a $20-\mathrm{W}$ diode-pumped laser requires only $80 \mathrm{~W}$, and must dissipate only $60 \mathrm{~W}$ of heat. Fiber lasers can convert more of the pump light into output light, with the wallplug efficiency reaching about $30 \%$ for ytterbium-fiber la- sers. Moreover, diode-pumped lasers are smaller as well as more efficient, as evidenced by the use of diode-pumped frequency-doubled neodymium lasers as green laser pointers, available for less than $\$ 50$ on the Internet.

Diode pumping enables new laser designs. Diodes couple easily and efficiently to optical fibers, making fiber lasers simple and practical. Pump diodes also can illuminate thin disks of doped ceramics resting on heat sinks, which can generate kilowatt-class powers in suitable laser cavities. A new family of optically pumped semiconductor lasers (OPSLs) can generate wavelengths unavailable from diode lasers because they don't require a junction or internal structures for current confinement. Instead, they rely on diode pumping through their surfaces to excite laser emission, which oscillates in a cavity similar to that of thin-disk lasers to deliver watts of power. OPSLs emit watt-class powers, and can be frequency-doubled from the near-IR into the visible to produce wavelengths previously available only from gas lasers, such as the 488-nm argon-ion line and the 577-nm line now considered optimum for treating diabetic retinopathy.

The high efficiency of diode pumping has made solid state lasers viable contenders for the tough job of defending against rocket, artillery and mortar attacks on the battlefield. Chemical lasers remain the most powerful type available, and in the Tactical High-Energy Laser demonstration, a DF chemical laser showed it should shoot down rockets and mortars by tracking and heating them until they exploded in the air. But field commanders didn't want a weapon system that required special chemical fuels; they wanted a solid state laser that could run off a standard mobile diesel generator.

To see if solid state lasers were up to the task, the Armed Services launched the Joint High Power Solid State Laser (JHPSSL) program. In early 2009, a Northrop Grumman diode-pumped ceramic slab oscillator-amplifier met the challenge. Seven $15-\mathrm{kW}$ amplifier chains tiled their outputs together to deliver ${ }^{165}$ a continuous $100-\mathrm{kW}$ beam for five mins. In early 2010, Textron Systems reached the same performance goal with its own design. ${ }^{166}$ Those are impressive achievements, although years will be necessary to move from the laboratory systems to one able to shoot down target missiles. Major challenges remain, including developing cooling systems and optics that can operate reliably under battlefield conditions, and designing lasers that are mobile and affordable. Yet even if solid state lasers never take out a single enemy rocket, the technology for building compact portable high-power lasers is likely to find industrial applications.

Some new laser types have also emerged during the solid state revolution. One important example is the quantum-cascade laser, based on intersubband transitions in a semiconductor. Electrons pass through a series of multiple-quantum-well heterostructures with a strong bias across the stack. The quantum wells trap the electrons in an upper energy state, where they can be stimulated to emit light, then drop to a lower level where they can tunnel out of that quantum well to one with lower energy. The structure is designed so the electron releases the same amount of energy in each transition, so it emits many photons while cascading through the series of quantum wells.

Rudolf F. Kazarinov and R. A. Suris ${ }^{167}$ originally pro- 
posed the idea of laser transitions on subbands in the conduction band of such superlattice structures in 1971, but it remained unrealized for more than two decades. Federico Capasso and colleagues at Bell Labs succeeded in 1994 using molecular-beam epitaxy and bandgap engineering technology that didn't exist when the idea was proposed. In their first experiments, they produced ${ }^{168} 8-\mathrm{mW}$ pulses at $4.2 \mu \mathrm{m}$. The technology has been developed extensively since 1994, making quantum-cascade lasers excellent sources for most applications from the mid-IR to the terahertz band.

Terahertz radiation has become a hot topic, particularly for security imaging applications, although the technology is still young. Quantum cascade lasers are not the only laser sources of terahertz radiation. Short, intense laser pulses can generate bursts of terahertz radiation when they hit suitable targets. Difference-frequency generation also can generate terahertz radiation.

\section{State-of-the-Art Lasers in $\mathbf{2 0 1 0}$}

Laser science and technology are remarkably varied and vigorous in 2010. Other articles in this issue sample many important areas, but it is impossible to cover the field comprehensively in anything short of an encyclopedia. Instead, I will close by noting some developments that particularly impress me after 35 years of writing about lasers.

- Femtosecond frequency combs were an elegant demonstration of our mastery of light when Theodor Hänsch and John Hall demonstrated them in the laboratory. Now the technology has been extended from Tisapphire lasers to fiber lasers, which are being developed for applications such as orbiting optical clocks for future navigation systems. Laboratory systems have demonstrated they can measure radial velocity with precision of $1 \mathrm{~cm} / \mathrm{s}$, more than enough to spot an Earth-sized planet orbiting another star if the system is deployed in space. ${ }^{169}$

- Broadband pulses generated by a fiber laser and a chirped-pulse fiber amplifier were compressed to just a single cycle of the light wave by Alfred Leitenstorfer and colleagues at the University of Konstanz in Germany. $^{170}$

- Plasmon lasers have generated laser light from objects smaller than a wavelength. ${ }^{171}$

- Peak powers of short pulses have reached the petawatt level, enabling new classes of physics experiments at incredible power densities. European scientists plan to go even further with the Extreme Light Infrastructure, ${ }^{172}$ generating pulses with attosecond durations and exawatt peak powers.

- The National Ignition Facility at the Lawrence Livermore National Laboratory has generated pulses of more than a megajoule, and is on target to reach its 1.8-MJ design goal. ${ }^{173}$

- The Linac Coherent Light Source, a free-electron laser generating 80 -fs pulses containing around $10^{13} \mathrm{x}$-ray photons at 0.15 to $1.5 \mathrm{~nm}$ is up and running at the SLAC National Accelerator Laboratory in California, using $1 \mathrm{~km}$ of the venerable 2-mi SLAC Linear Accelerator. It is the world's shortest-wavelength laser, and boosts x-ray energy available for spectroscopy at
Table 1 Laser-related Nobel Prizes through 2009.

\begin{tabular}{|c|c|c|}
\hline Year and Prize & Recipients & Research \\
\hline 1964 Physics & $\begin{array}{l}\text { Charles Townes, } \\
\text { Nikolai } \\
\text { Basov, Alexander } \\
\text { Prokhorov }\end{array}$ & $\begin{array}{l}\text { Fundamental research } \\
\text { leading to the maser and } \\
\text { laser }\end{array}$ \\
\hline 1971 Physics & Dennis Gabor & $\begin{array}{l}\text { Holography (made } \\
\text { practical by laser) }\end{array}$ \\
\hline 1981 Physics & $\begin{array}{l}\text { Nicolaas } \\
\text { Bloembergen, } \\
\text { Arthur Schawlow }\end{array}$ & $\begin{array}{l}\text { Development of laser } \\
\text { spectroscopy }\end{array}$ \\
\hline 1997 Physics & $\begin{array}{l}\text { Steven Chu, Claude } \\
\text { Cohen-Tannoudji, } \\
\text { William Phillips }\end{array}$ & $\begin{array}{l}\text { Laser trapping and } \\
\text { cooling of atoms }\end{array}$ \\
\hline 1999 Chemistry & Ahmed Zewail & $\begin{array}{l}\text { Studies of chemical } \\
\text { reaction dynamics on } \\
\text { femtosecond time scales }\end{array}$ \\
\hline 2000 Physics & $\begin{array}{l}\text { Zhores Alferov, } \\
\text { Herbert } \\
\text { Kroemer }\end{array}$ & $\begin{array}{l}\text { Invention of } \\
\text { heterostructures, } \\
\text { essential for high-speed } \\
\text { optoelectronics }\end{array}$ \\
\hline 2001 Physics & $\begin{array}{l}\text { Eric Cornell, Carl } \\
\text { Wieman, Wolfgang } \\
\text { Ketterle }\end{array}$ & $\begin{array}{l}\text { Producing Bose-Einstein } \\
\text { condensates, sometimes } \\
\text { called "atom lasers" }\end{array}$ \\
\hline $\begin{array}{l}2005 \text { Physics } \\
\text { (separate } \\
\text { citations) }\end{array}$ & Roy Glauber & $\begin{array}{l}\text { Quantum theory of } \\
\text { optical coherence }\end{array}$ \\
\hline $\begin{array}{l}2005 \text { Physics } \\
\text { (separate } \\
\text { citations) }\end{array}$ & $\begin{array}{l}\text { John Hall, Theodor } \\
\text { Hänsch }\end{array}$ & $\begin{array}{l}\text { Ultraprecise laser } \\
\text { spectroscopy and } \\
\text { frequency-comb } \\
\text { generation }\end{array}$ \\
\hline 2009 Physics & Charles Kao & $\begin{array}{l}\text { Light transmission in } \\
\text { optical fibers for } \\
\text { telecommunications }\end{array}$ \\
\hline
\end{tabular}

particular lines by a factor of $10^{8}$. "This is a landmark event in the history of light-source science, which will open up vast new areas for scientific exploration," wrote Brian McNeil of the University of Strathcylde when it opened. ${ }^{174}$

Lasers have come a long way in half a century. In monetary terms, Laser Focus World predicts that global laser sales will approach $\$ 6$ billion in 2010, with just over half going to communications and information processing, a quarter for materials processing, and the balance for other applications from medicine to military. ${ }^{175}$ That doesn't count the other equipment used with the lasers, or the value of laser-based systems.

Lasers have also come a long way in their contribution to human knowledge. Table 1 lists the 19 laser-related Nobel prizes awarded through 2009 . In the 1960 s, laser beams reached the Moon before humans. More recently, laser beams have mapped Mars and the Moon.

Finally, lasers have become integral parts of our technological society. Lasers are at the very heart of the Internet, 
sending signals through the optical fibers that make up the backbone of the global telecommunications network. In 1988, the TAT- 8 submarine cable began service, the first fiber-optic cable to cross the Atlantic Ocean. It was a landmark in global communications. More submarine fiber cables followed, adding so much more capacity across the Atlantic that when TAT-8 suffered a hardware failure in 2002 , it was quietly retired because it wasn't worth repairing. Thanks to that global network, we can roam the world on the Internet.

Charles Kao's visionary quest to develop fiber-optic communications earned him the 2009 Nobel Prize in Physics, but that award is also a tribute to the laser community's success in helping to develop a technology that is making the world accessible to most of its people.

\section{Acknowledgments}

Thanks to Colin Webb for his comments on an earlier draft and for sharing a preprint of his history of pulsed gas lasers. Thanks to Ron Driggers for the invitation to write this article. And thanks to the many people who have generously given their time over the years talking with me about lasers and their history.

\section{Appendix: Timeline of Events}

This timeline summarizes events listed in this review, but is not intended to be comprehensive.
Date
Event

1916

1928

1940

1951

1954

Summer 1957

October 1957

November 1957

December 1958

1959

May 16, 1960

Summer 1960

July 8, 1960

November 1960

December 12, 1960

1961

1961

1961

1961

1961

November 22, 1961

1962

1962

1962

1962
Albert Einstein proposes stimulated emission

Indirect evidence for stimulated emission reported by Rudolf Ladenburg Light amplification by stimulated emission proposed by Valentin Fabrikant Stimulated emission at $50 \mathrm{kHz}$ observed by Edward Purcell and Robert Pound, Harvard

Charles Townes and James Gordon produce first microwave maser at $24 \mathrm{GHz}$ at Columbia University

Townes starts investigating optical maser

Townes talks with Gordon Gould about optical pumping and optical maser Gould coins word "laser" and proposes Fabry-Pérot resonator in first notebook Townes and Arthur Schawlow publish detailed "optical maser" proposal in Physical Review

ARPA issues $\$ 999,000$ contract to TRG to develop laser based on Gould proposal

Theodore Maiman demonstrates ruby laser at Hughes Research Labs

TRG Inc., Bell Labs duplicate ruby laser

Headlines announce laser discovery, predict uses from communications to weapons

Peter Sorokin and Mirek Stevenson, IBM, make first four-level solid state laser, Uranium in $\mathrm{CaF}_{2}$

Ali Javan, William Bennett, and Donald Herriott of Bell Labs make heliumneon laser, the first continuous-wave laser and the first gas laser

First neodymium laser in calcium tungstate; Leo Johnson and Kurt Nassau, Bell Labs

First neodymium-glass laser, Elias Snitzer, American Optical

Second harmonic of ruby generated by Peter Franken

Trion Instruments founded in Ann Arbor to make lasers

Quantatron founded by Maiman to make lasers; later becomes Korad

Ruby laser repairs detached retina in first patient at Harkness Eye Institute in New York

Red helium-neon laser invented by Alan White and Dane Rigden, Bell First semiconductor diode laser, Robert Hall, GE R\&D Labs, followed in weeks by three other groups

Spectra-Physics and Perkin-Elmer introduce $\$ 8000$ IR helium-neon laser in March; sales take off when they introduce red version in autumn Lawrence Livermore National Lab forms groups to study prospects for laser fusion 
Date Event

1962

1963

1963

1963

1964

1964

1964

1964

1964

1965

1965

1965

1965

1965

1966

1966

1966

1967

1967

1968

1969

1970

1970

1970

1970

1971

1972

1974

1974

1974

1976

1976

1977

1978

1979

1980

1980
Air Force Chief of Staff Gen. Curtis LeMay praises prospects for laser nuclear defense

Herbert Kroemer proposes heterostructures to improve diode lasers. Zhores Aleferov and Rudolf Kazarinov at Ioffe Institute in Russia file patent on double heterostructure laser

First ion laser demonstrated in mercury by Earl Bell at Spectra-Physics

Nitrogen laser invented by H. G. Heard

Snitzer demonstrates first fiber amplifier

William Bridges discovers pulsed argon-ion laser at Hughes; Eugene Gordon develops cw argon at Bell

First 3-D laser holograms displayed by Emmett Leith and Juris Upatnieks

Kumar Patel makes $\mathrm{CO}_{2}$ laser at Bell Labs

Joseph Geusic an LeGrand Van Uitert make first Nd-YAG laser at Bell

Kumar Patel reaches $200 \mathrm{~W}$ cw from $\mathrm{CO}_{2}$ laser

Coherent Radiation founded to manufacture $\mathrm{CO}_{2}$ lasers

William Silfvast and Grant Fowles make helium-cadmium laser

J.V.V. Kasper and George C. Pimentel make first chemical laser, $\mathrm{HCl}$

Coherent anti-Stokes Raman spectroscopy demonstrated by Robert Terhune at Ford

Peter Sorokin makes first dye laser at IBM; Fritz P. Schaefer independently invents dye at Max Planck Institute

Charles Kao and George Hockham propose communications through low-loss single-mode optical fibers

Ed Gerry and Arthur Kantrowitz invent gasdynamic $\mathrm{CO}_{2}$ laser, which eventually reaches hundreds of kilowatts

Dye laser tuned for the first time by Bernard Soffer and B. B. McFarland at Korad

Jack Dyment develops stripe-geometry diode laser

Argon-laser treatment of diabetic retinopathy developed by Francis

L'Esperance, Eugene Gordon, and Ed Labuda

Ruby laser pulses range the moon by bouncing off retroreflector placed by Apollo 11 astronauts

Nikolai Basov of Lebedev Institute reports pulsed uv lasing by xenon excimers

Zhores Alferov demonstrates first room-temperature cw diode laser

First low-loss optical fiber made by Robert Maurer, Donald Keck, and Peter

Schultz at Corning

Ben Snavely demonstrates cw dye laser at Kodak

Rudolf Kazarinov and R. A. Suris proposed concept behind quantum cascade laser

Erich Ippen and Charles Shank produce 1.5-ps pulses

First laser scanner demonstrated in a supermarket

Rare-gas halide excimer lasers invented; several types demonstrated

Two-photon Doppler-free spectroscopy developed independently by Theodor

Hänsch at Stanford and David Pritchard at MIT

Bell Labs accelerated aging tests predict million-hour lifetimes for GaAs diode lasers

J. Jim Hsieh operates InGaAsP diode emitting at $1.25 \mu \mathrm{m}$ at room temperature

John M. J. Madey operates first free-electron laser oscillator

MCA-Philips begins test-marketing He-Ne laser player of 12-in. videodisks

Philips shows prototype compact disk player

Bell announces plans for TAT-8, first transatlantic fiber-optic cable

Supermarket scanners become common 
Date Event

$\begin{array}{ll}1982 & \text { Peter Moulton develops Ti-sapphire laser } \\ 1982 & \text { Audio compact disk players introduced in Japan } \\ 1983 & \text { Ronald Reagan launches Strategic Defense Initiative } \\ 1984 & \text { First commercial diode-pumped neodymium lasers emit } 100 \mathrm{~mW} \mathrm{cw} \\ 1985 & \text { Spectra Diode Labs introduced 200-mW array of } 10 \mathrm{cw} \text { GaAlAs diode laser } \\ & \text { stripes } \\ 1985 & \text { Sony makes cw AlGaInP diode emitting at } 671 \mathrm{~nm} \text { in red } \\ 1985 & \text { First room-temperature VCSEL by Kenichi Iga } \\ 1986 & \text { David Payne makes Er-fiber laser tunable across } 25 \mathrm{~nm} \text { near } 1535 \mathrm{~nm} \\ 1987 & \text { Payne reports } 26-\text { dB gain at } 1536 \mathrm{~nm} \text { in erbium-doped fiber amplifier } \\ 1987 & \text { Pulses from dye laser compressed to } 6 \text { fs by Richard Fork at Bell } \\ 1988 & \text { TAT-8, the first transatlantic fiber cable, is completed } \\ 1989 & \text { Spectra Diode Labs produces 76 W cw from 1-cm diode array } \\ 1989 & \text { Isamu Akasaki demonstrates blue LED of GaN } \\ 1994 & \text { Nichia Chemical offers 450-nm nitride LEDs with 2\% electrical conversion } \\ & \text { efficiency } \\ 1994 & \text { Federico Capasso at Bell Labs demonstrates quantum cascade laser } \\ 1995 & \text { Pulse length of Ti-sapphire reaches } 8 \text { fs } \\ 1996 & \text { Shuji Nakamura of Nichia reports first blue diode laser, made from InGaN } \\ 2000 & \text { Ti-sapphire pulses compressed to } 5 \text { fs } \\ 2000 & \text { Peak of technology stock bubble; NASDAQ exceeds } 5000 \text { during OFC } 2000 \text { in } \\ 2002 & \text { March } \\ & \text { TAT-8 submarine cable retired after failure because its capacity was too small } \\ & \text { to justify the cost of repairs }\end{array}$

\section{References}

1. "Electronics: The Death Ray Next?" Newsweek, July 18, 1960, p. 78.

2. John A. Osmundsen, "Light amplification claimed by scientist," New York Times, July 8, 1960, p. 1; "Light amplifier extends spectrum," Electronics, July 22, 1960, p. 43.

3. G. Basalla, The Evolution of Technology, Cambridge University Press, Cambridge (1988)

4. A. Einstein, "On the quantum theory of radiation," in Laser Theory, F. A. Barnes, ed., pp. 5-21, IEEE Press, New York (1972).

5. R. Ladenburg, "Research on the anomalous dispersion of gases," $Z$. Phys. 48, 15-25 (1928).

6. V. A. Fabrikant, "Emission mechanism of a gas discharge," Trudy VEL 41, 236 (1940); reprinted in English in V. A. Fabrikant, Selected Works p. 133, privately printed, Moscow (2007).

7. W. E. Lamb Jr. and R. C. Retherford, "Fine structure of the hydrogen atom, part I," Phys. Rev. 79, 549-572 (1950).

8. E. M. Purcell and R. V. Pound, "A nuclear spin system at negative temperature" Phys. Rev. 81, 279-280 (1951).

9. J. P. Gordon, H. J. Zeiger, and C. H. Townes, "Molecular microwave oscillator and new hyperfine structure in the microwave spectrum of $\mathrm{NH}_{3}$," Phys. Rev. 95, 282-284 (1954).

10. J. Hecht, Beam: The Race to Make the Laser, Oxford University Press, New York (2005)

11. N. Taylor, Laser: The Inventor, the Nobel Laureate, and the 30-Year Patent War, Simon \& Schuster, New York (2000).

12. A. L. Schawlow and C. H. Townes, "Infrared and optical masers," Phys. Rev. 112, 1940-1949 (1958).

13. A. Javan, "Possibility of production of negative temperature in gas discharges," Phys. Rev. Lett. 3(2), 87-89 (1959).

14. G. Gould, "Apparatus for intensifying electromagnetic radiation," UK Patent Specification 953,722 (filed Apr. 1, 1960; issued Apr. 2, 1964).

15. T. H. Maiman, "Optical and microwave-optical experiments in ruby," Phys. Rev. Lett. 4(11), 564-566 (1960).

16. J. Hecht, Beam: The Race to Make the Laser, pp. 183-194, Oxford University Press, New York (2005).

17. T. H. Maiman, "Stimulated optical radiation in ruby," Nature 187, 493 (1960).

18. T. H. Maiman, "Stimulated optical emission in fluorescent solids, Part I. Theoretical considerations," Phys. Rev. 125, 1145-1150 (1961); T.
H. Maiman, R. H. Hoskins, I. J. D'Haenens, C. K. Asawa, and V. Evtuhov, "Stimulated optical emission in fluorescent solids II, Spectroscopy and stimulated emission in ruby," Phys. Rev. 125, 11511157 (1961)

19. P. P. Sorokin and M. J. Stevenson, "Stimulated infrared emission from trivalent uranium," Phys. Rev. Lett. 5, 557-559 (1960).

20. P. P. Sorokin and M. J. Stevenson, "Solid-state optical maser using divalent samarium in calcium fluoride," IBM J. Res. Dev. 5, 56-58 (1961).

21. A. L. Schawlow and G. E. Devlin, "Simultaneous optical maser action in two ruby satellite lines," Phys. Rev. Lett. 6(3), 96-98 (1961); I. Wieder and L. R. Sarles, "Stimulated optical emission from exchange-coupled ions of $\mathrm{Cr}^{+++}$in $\mathrm{Al}_{2} \mathrm{O}_{3}$, , Phys. Rev. Lett. 6(3), 95-96 (1961).

22. Ali Javan, W. R. Bennett Jr., and D. R. Herriott, "Population inversion and continuous optical maser oscillation in a gas discharge containing a He-Ne mixture," Phys. Rev. Lett. 6(3), 106-110 (1961).

23. G. D. Boyd and J. P. Gordon, "Confocal multimode resonator for millimeter through optical wavelength masers," Bell Syst. Tech. J. 40, 489-508 (1961).

24. J. Hecht, "History of gas lasers. Part 1: Continuous-wave gas lasers," Opt. Photonics News 21(1), 16-23 (2010).

25. A. D. White and J. D. Rigden, "Continuous gas maser operation in the visible," Proc. IRE 50(7), 1697 (1962)

26. L. F. Johnson and K. Nassau, "Infrared fluorescence and stimulated emission of $\mathrm{Nd}^{+3}$ in $\mathrm{CaWO}_{4}$," Proc. IRE 49(11), 1704-1705 (1961).

27. L. F. Johnson, G. D. Boyd, K. Nassau, and R. R. Soden, "Continuous operation of a solid-state optical maser," Phys. Rev. 126, 1406-1409 (1962).

28. J. E. Geusic, H. W. Marcos, and L. G. Van Uitert, "Laser oscillations in Nd-doped yttrium aluminum, yttrium gallium, and gadolinium garnets," Appl. Phys. Lett. 4, 182-184 (1964).

29. "Oral history interview-Elias Snitzer," conducted Aug. 6, 1984, posted at http://www.aip.org/history/ohilist/5057.html.

30. E. Snitzer, "Optical maser action of $\mathrm{Nd}^{+3}$ in barium crown glass," Phys. Rev. Lett. 7(12), 444-446 (1961).

31. C. J. Koester and E. Snitzer, "Amplification in a fiber laser," Appl. Opt. 3(10), 1182-1186 (1964).

32. P. Rabinowitz, S. Jacobs, and G. Gould, "Continuous optically pumped Cs laser," Appl. Opt. 15(7), 513-516 (1962). 
33. J. von Neumann, "Notes on the photon-disequilibrium-amplifier scheme, September 16, 1953," IEEE J. Quantum Electron. QE-23(6), 658-673 (1987)

34. R. Dupuis, "An introduction to the development of the semiconductor laser," IEEE J. Quantum Electron. QE-23(6), 651-657 (1987).

35. H. J. Round, Electrical World, p. 309 (Feb. 9, 1907).

36. R. Braunstein, "Radiative transitions in semiconductors," Phys. Rev 99, 1892-1893 (1955).

37. R. J. Keyes and T. M. Quist, "Recombination radiation emitted by gallium arsenide," Proc. IRE 50(8), 1822-1823 (1962).

38. R. H. Rediker, "Research at Lincoln Laboratory leading up to the development of the injection laser in 1962," IEEE J. Quantum Electron. QE-23(6), 692-695 (1987)

39. R. N. Hall, G. E. Fenner, J. D. Kingsley, T. J. Soltys, and R. O. Carlson, "Coherent light emission from GaAs junctions," Phys. Rev. Lett. 9(9), 366-368 (1962).

40. M. I. Nathan, W. P. Dumke, G. Burns, F. H. Dill Jr., and G. Lasher, "Stimulated emission of radiation from GaAs p-n junctions," Appl. Phys. Lett. 1(3), 62-64 (1962); T. M. Quist, R. H. Rediker, R. J. Keyes, W. E. Krag, B. Lax, A. L. McWhorter, and H. J. Zeiger, "Semiconductor maser of GaAs," Appl. Phys. Lett. 1(4), 91-92 (1962).

41. N. Holonyak Jr. and S. F. Bevacqua, "Coherent (visible) light emission from $\mathrm{Ga}\left(\mathrm{As}_{1-\mathrm{x}} \mathrm{P}_{\mathrm{x}}\right)$ junctions," Appl. Phys. Lett. 1(4), 82-83 (1962).

42. T. Maiman, The Laser Odyssey, Laser Press, Blaine, WA (2000).

43. S. F. Johnston, Holographic Visions: A History of a New Science, pp. 170-171, Oxford University Press, Oxford (2006)

44. J. L. Bromberg, The Laser in America 1950-1970, pp. 122-123, MIT Press, Cambridge (1991)

45. J. Baar, "Death ray visualized as H-bomb successor," Washington Post and Times Herald, May, 6, 1958, p. A8.

46. N. Taylor, Laser: The Inventor, the Nobel Laureate, and the 30-Year Patent War, pp. 87-91, Simon \& Schuster, New York (2000).

47. J. Hecht, Beam: The Race to Make the Laser, pp. 191-192, Oxford University Press, New York (2005).

48. C. Koester and C. J. Campbell, "The first clinical application of the laser," Lasers in Ophthalmology: Basic, Diagnostic, and Surgical Aspects: A Review, F. Fankhauser and S. Kwasniewska, Eds., pp. 115-117, Kugler Publications, The Hague (2003).

49. P. A. Franken, A. E. Hill, C. W. Peters, and G. Weinreich, "Generation of optical harmonics," Phys. Rev. Lett. 7(4), 118-119 (1961).

50. A. Parker, "Empowering light: Historic accomplishments in laser research," Sci. Technol. Rev. 20 (Sept. 2002), https://www.llnl.gov/str/ September02/September50th.html, viewed Aug. 21, 2010.

51. http://journalism.missouri.edu/faculty/stuart-loory.html, viewed Dec. $22,2009$.

52. S. H. Loory, "The incredible laser," This Week, Nov. 11, 1962, p 7-8, 25.

53. D. Gabor, "A new microscopic principle," Nature 161, 777-778 (1948).

54. E. N. Leith and J. Upatnieks, "Reconstructed wavefronts and communication theory," J. Opt. Soc. Am. 52(10), 1123-1130 (1962).

55. J. Hecht, "Application pioneer interview: Emmett Leith," Laser Phys. 5(4), 53-58 (1986)

56. E. N. Leith and J. Upatnieks, "Wavefront reconstruction with diffused illumination and three-dimensional objects," J. Opt. Soc. Am. 54(11), 1295-1301 (1964).

57. C. K. N. Patel (interview) "The Carbon Dioxide Laser" in J. Hecht, Laser Pioneers: Revised Edition, pp. 191-204, Academic Press, San Diego, CA (1991).

58. C. K. N. Patel, "Continuous-wave laser action on vibrationalrotational transitions of $\mathrm{CO}_{2}, "$ Phys. Rev. 136(5A), A1187-A1193 (1964).

59. C. K. N. Patel, P. K. Tien, and J. H. McFee, "CW high-power $\mathrm{CO}_{2}-\mathrm{N}_{2}-\mathrm{He}$ laser," Appl. Phys. Lett. 7(11), 290-292 (1965).

60. J. L. Bromberg, The Laser in America 1950-1970, p. 175, MIT Press, Cambridge (1991)

61. E. Watson, "Founder looks back as Coherent marks 40 years in business," Laser Focus World 42(8), 11-12 (2006).

62. J. L. Bromberg, The Laser in America 1950-1970, p. 165, MIT Press, Cambridge (1991)

63. W. E. Bell, "Visible laser transitions in $\mathrm{Hg}^{+}, "$ Appl. Phys. Lett. 4(2), 34-35 (1964).

64. W. Bridges, "The Ion Laser" (interview), pp. 205-225 in J. Hecht, Laser Pioneers: Revised Edition, Academic Press, San Diego, CA (1990).

65. W. B. Bridges, "Laser oscillation in singly ionized argon in the visible spectrum," Appl. Phys. Lett. 4(7), 128-130 (1964); erratum: Appl. Phys. Lett. 5(2), 39 (1964).

66. J. Hecht, "History of gas lasers, part 1, continuous-wave gas lasers," Opt. Photonics News 21(1), 16-23 (2010).

67. E. I. Gordon and E. F. Labuda, "Gas pumping in continuously operated ion lasers," Bell Syst. Tech. J. 43, 1827-1829 (1964); E. I. Gor- don, E. F. Labuda, and W. B. Bridges, "Continuous visible laser action in singly ionized argon, krypton, and xenon," Appl. Phys. Lett. 4(10), 178-180 (1964)

68. W. T. Silfvast, G. R. Fowles, and B. D. Hopkins, "Laser action in singly ionized Ge, Sn, Pb, In, Cd and Zn," Appl. Phys. Lett. 8(6), 318-319 (1966).

69. W. T. Silfvast, "Efficient CW laser oscillation at $4416 \AA$ Cd(II)," Appl. Phys. Lett. 13(5), 169-171 (1968).

70. W. T. Silfvast, "Metal Vapor Lasers" (interview), pp. 227-242 in Jeff Hecht, Laser Pioneers: Revised Edition, Academic Press, San Diego, CA (1991).

71. W. T. Walter, M. Piltch, M. N. Solimene, and G. Gould, "6C3efficient pulsed gas discharge lasers," IEEE J. Quantum Electron. QE-2(9), 474-479 (1966).

72. J. C. Polanyi, "Proposal for an infrared maser dependent on vibrational excitation," J. Chem. Phys. 34, 347-348 (1961).

73. J. V. V. Kasper and G. C. Pimentel, "HCl chemical laser," Phys. Rev Lett. 14(10), 352-354 (1965)

74. P. P. Sorokin and J. R. Lankard, "Stimulated emission observed from an organic dye, chloro-aluminum phthalocyanine," IBM J. Res. Dev 10(3), 162-163 (1966).

75. F. P. Schäfer, W. Schmidt, and J. Volze, "Organic dye solution laser," Appl. Phys. Lett. 9(8), 306-309 (1966)

76. B. H. Soffer and B. B. McFarland, "Continuously tunable, narrowband organic dye lasers," Appl. Phys. Lett. 10(10), 266-267 (1967).

77. O. G. Peterson, S. A. Tuccio, and B. B. Snavely, "CW operation of an organic dye solution laser," Appl. Phys. Lett. 17(6), 245-247 (1970).

78. $\mathrm{R}$. Newman, "Excitation of the $\mathrm{Nd}^{3+}$ Fluorescence in $\mathrm{CaWO}_{4}$ by recombination radiation in GaAs," J. Appl. Phys. 34(2), 437 (1963).

79. R. J. Keyes and T. M. Quist, "Injection luminescent pumping of $\mathrm{CaF}_{2}: \mathrm{U}^{3+}$ with GaAs diode lasers," Appl. Phys. Lett. 4(3), 50-52 (1964).

80. Z. J. Kiss and R. J. Pressley, "Crystalline solid lasers," Appl. Opt. 5(10), 1474-1486 (1966).

81. C. G. Young, "Glass lasers," Proc. IEEE 57(7), 1267-1289 (1969).

82. J. Hecht, City of Light: The Story of Fiber Optics, Oxford, New York (1999).

83. E. I. Gordon, "Use of lasers in ophthalmic surgery," IEEE J. Sel. Top. Ouantum Electron. 6(6), 1116-1121 (2000).

84. H. Kroemer, "A proposed class of heterojunction injection lasers," Proc. IEEE 51(12), 1782-1783 (1963).

85. Z. I. Alferov, V. M. Andreev, V. I. Korol'kov, D. N. Trat'yakov, and V. M. Tuchkevich, "High-voltage $p-n$ junctions in $\mathrm{Ga}_{\mathrm{x}} \mathrm{Al}_{1-\mathrm{x}}$ As crystals," Fiz. Tekh. Poluprovodn. 1, 1579 (1967); published in English in Sov. Phys. Semicond. 1, 1313 (1968)

86. H. Rupprecht, J. M. Woodall, and G. D. Pettit, "Efficient visible electroluminescence at $300{ }^{\circ} \mathrm{K}$ from $\mathrm{Ga}_{1-x} \mathrm{Al}_{x} \mathrm{As} p$ - $n$ junctions grown by liquid-phase epitaxy," Appl. Phys. Lett. 11(3), 81-83 (1967).

87. J. C. Dyment, "Hermite-Gaussian mode patterns in GaAs junction lasers," Appl. Phys. Lett. 10(3), 84-86 (1967).

88. Zh. I. Alferov, V. M. Andreev, D. Z. Garbuzov, Yu. V. Zhilyaev, E. P. Morozov, E. L. Portnoi, and V. G. Trofim, "Effect of the heterostructure parameters on the laser threshold current and the realization of continuous generation at room temperature," Fiz. Tekh. Poluprovodn. 4, 1826-1829 (1970), English translation, in Sov. Phys. Semicond. 4, $1573-1575$ (1971).

89. I. Hayashi, M. B. Panish, P. W. Foy, and S. Sumski, "Junction lasers which operate continuously at room temperature," Appl. Phys. Lett. 17(3), 109-111 (1970).

90. R. L. Hartman, N. E. Schumaker, and R. W. Dixon, "Continuously operated (Al,Ga) As double-heterostructure lasers with $70^{\circ} \mathrm{C}$ lifetimes as long as two years," Appl. Phys. Lett. 31(11), 765-759 (1977).

91. J. H. Hsieh and C. C. Shen, "Room-temperature cw operation of buried-stripe double-heterostructure GaInAsP/InP diode lasers," Appl. Phys. Lett. 30(8), 429-431 (1977)

92. J. Hecht, Laser Pioneers: Revised Edition, pp. 41-42, Academic Press, San Diego, CA (1992)

93. E. T. Gerry, "Gasdynamic lasers," IEEE Spectrum 7(11), 51 (1970).

94. J. Hecht "Half a century of laser weapons," Opt. Photonics News 20(2), 14-21 (2009)

95. F. G. Houtermans, "Über Massen-Wirkung im optischen Spektralgebiet un die Möglichkeit absolut negativer Absorption für einige Fälle von Molekülspektren (Licht-Lawine)," Helv. Phys. Acta 33, 933 (1960), http://www.rp-photonics.com/excimer_lasers.html.

96. N. G. Basov, V. A. Danilychev, and Yu. M. Popov, "Stimulated emission in the vacuum ultraviolet region," Sov. J. Ouantum Electron 1(1) $18-22$ (1971)

97. H. A. Koehler, L. J. Ferderber, D. L. Redhead, and P. J. Ebert, "Stimulated VUV emission in high-pressure xenon excited by highcurrent relativistic electron beams," Appl. Phys. Lett. 21(5), 198-200 (1972).

98. C. Webb, "History of gas lasers, II, pulsed lasers," Opt. Photonics News 21(2), 20-27 (2010). 
99. J. E. Velazco and D. W. Setser, "Bound-free emission spectra of diatomic xenon halides," J. Chem. Phys. 62(5), 1990-1991 (1975).

100. S. K. Searles and G. A. Hart, "Stimulated emission at $281.8 \mathrm{~nm}$ from XeBr," Appl. Phys. Lett. 27(4), 243-244 (1975).

101. C. Webb, "History of gas lasers, II, pulsed lasers," Opt. Photonics News 21(2), 20-27 (2010).

102. J. J. Ewing and C. A. Brau, "Laser action on the ${ }^{2} \Sigma_{1 / 2}^{+} \rightarrow^{2} \Sigma_{1 / 2}^{+}$bands of $\mathrm{KrF}$ and XeCl," Appl. Phys. Lett. 27(6), 350-351 (1975); "354-nm laser action on XeF," Appl. Phys. Lett. 27(8), 435-436 (1975).

103. E. R. Ault, R. S. Bradford Jr., and M. L. Bhaumik, "High-power xenon fluoride laser," Appl. Phys. Lett. 27(7), 413-415 (1975).

104. G. C. Tisone, A. K. Hays, and J. M. Hoffman, "100 MW, 248.4 nm, $\mathrm{KrF}$ laser excited by an electron beam," Opt. Commun. 15(2), 188189 (1975)

105. J. H. (J. Hecht), "Excimer is discharge pumped," Laser Focus 11(12), 10-18 (1975); R. Burnham, N. W. Harris, and N. Djeu, "Xenon fluoride laser excitation by transverse electric discharge," Appl. Phys. Lett. 28(2), 86-87 (1976).

106. J. M. Hoffman, A. K. Hays, and G. C. Tisone, "High power uv noble-gas-halide laser," Appl. Phys. Lett. 28(9), 538-539 (1976).

107. H. G. Heard, "Ultra-violet gas laser at room temperature," Nature 200, 667-668 (1963).

108. The Amateur Scientist, Scientific American, June 1974, p. 122; see also http://www.jossresearch.org/lasers/nitrogen/ circuitboardlaser.html

109. J. J. Ewing, "Excimer laser technology development," IEEE J. Sel. Top. Quantum Electron. 6(6), 1061-1073 (2000).

110. J. M. J. Madey, "Stimulated emission of bremsstrahlung in a periodic magnetic field," J. Appl. Phys. 42(5), 1906-1913 (1971).

111. L. Elias, W. M. Fairbank, J. M. J. Madey, H. A. Schwettmann, and T. I. Smith, "Observation of stimulated emission of radiation by relativistic electrons in a spatially periodic transverse magnetic field," Phys. Rev. Lett. 36(13), 717-720 (1976).

112. D. Deacon, L. Elias, J. M. J. Madey, G. J. Ramian, H. A. Schwettmann, and T. I. Smith, "First operation of a free-electron laser," Phys. Rev. Lett. 38(16), 892-894 (1977).

113. P. D. Maker and R. W. Terhune, "Study of optical effects due to an induced polarization third order in the electric field strength," Phys. Rev. 137(3A), A801-A818 (1965).

114. R. F. Begley, A. V. Harvey, and R. L. Byer, "Coherent anti-Stokes Raman spectroscopy," Appl. Phys. Lett. 25(7), 387-390 (1974).

115. D. Pritchard, J. Apt, and T. W. Ducas, "Fine structure of $\mathrm{Na} 4 \mathrm{~d}^{2} \mathrm{D}$ using high-resolution two-photon spectroscopy," Phys. Rev. Lett. 32(12), 641-642 (1974)

116. T. W. Hänsch, S. A. Lee, R. Wallenstein, and C. Wieman, "Dopplerfree two-photon spectroscopy of hydrogen 1S-2S," Phys. Rev. Lett. 34(6), 307-309 (1975).

117. W. E. Lamb Jr., "Theory of an optical laser," Phys. Rev. 134(6A), A1429-A1450 (1964).

118. E. P. Ippen, C. V. Shank, and A. Dienes, "Passive mode locking of the cw dye laser," Appl. Phys. Lett. 21(8), 348-350 (1972)

119. C. V. Shank and E. P. Ippen, "Subpicosecond kilowatt pulses from a mode-locked cw dye laser," Appl. Phys. Lett. 24(8), 373-375 (1974).

120. R. L. Fork, C. H. Brito Cruz, P. C. Becker, and C. V. Shank, "Compression of optical pulses to six femtoseconds by using cubic phase compensation," Opt. Lett. 12(6), 483-485 (1987)

121. L. F. Johnson, R. E. Dietz, and H. J. Guggenheim, "Optical maser oscillations from $\mathrm{Ni}^{2+}$ in $\mathrm{MgF}_{2}$ involving simultaneous emission of phonons," Phys. Rev. Lett. 11(7), 318-320 (1963).

122. J. C. Walling, O. G. Peterson, H. P. Jenssen, R. C. Morris, and E. W. O'Dell, "Tunable alexandrite lasers," IEEE J. Quantum Electron. QE-16(12), 1302-1315 (1980).

123. P. F. Moulton, "Spectroscopic and laser characteristics of Ti: $\mathrm{Al}_{2} \mathrm{O}_{3}, " J$ J. Opt. Soc. Am. B 3(1), 125-133 (1986).

124. D. E. Spence, P. N. Kean, and W. Sibbett "60-fsec pulse generation from a self-mode-locked Ti:sapphire laser," Opt. Lett. 16(1), 42-44 (1991).

125. A. Stingl, M. Lenzner, Ch. Spielmann, F. Krausz, and R. Szipöcs, "Sub-10-fs mirror-dispersion-controlled Ti:sapphire laser," Opt. Lett. 20(6), 602-604 (1995).

126. R. Ell, U. Morgner, F. X. KÃ Ârtner, J. G. Fujimoto, E. P. Ippen, V. Scheuer, G. Angelow, T. Tschudi, M. J. Lederer, A. Boiko, and B. Luther-Davies, "Generation of 5 -fs pulses and octave-spanning spectra directly from a Ti:sapphire laser," Opt. Lett. 26(6), 373-375 (2001).

127. W. Denk, J. H. Strickler, and W. W. Webb, "Two-photon laser scanning fluorescence microscopy," Science 248 73-76 (1990).

128. M. B. W. Graham, RCA and the VideoDisc: The Business of Research, p. 213, Cambridge University Press, Cambridge (1986).

129. http://www.homemediamagazine.com/news/laserdisc-officiallydead-14333, checked Dec. 26, 2009.
130. J. Hecht, "A half-century of laser weapons," Opt. Photonics News 20(2), 14-21 (2009).

131. R. Q. Fugate, B. L. Ellerbroek, C. H. Higgins, M. P. Jelonek, W. J. Lange, A. C. Slavin, W. J. Wild, D. M. Winker, J. M. Wynia, J. M Spinhirne, B. R. Boeke, R. E. Ruane, J. F. Moroney, M. D. Oliker, D. W. Swindle, and R. A. Cleis, "Two generations of laser-guidestar adaptive-optics experiments at the Starfire Optical Range," $J$. Opt. Soc. Am. A 11(1), 310-324 (1994)

132. D. R. Scifres, R. D. Burnham, and W. Streifer, "Phase-locked semiconductor laser array," Appl. Phys. Lett. 33(12), 1015-1017 (1978).

133. "Spectra Diode Labs 200-mW diode laser," Laser Appl. 4(12), 50 (1985).

134. G. L. Harnagel, D. L. Scifres, H. H. Kung, D. F. Welch, D. P. Worland, and P. S. Cross, "Four-watt continuous GaAlAs laser grown by metal-organic chemical vapor deposition," in Technical Digest, Topical Meeting on Integrated and Guide-Wave Optics, p. 42, Optical Society of America, Washington, D.C. (1986).

135. M. Sakamoto, D. F. Welch, J. G. Endriz, D. R. Scifres, and W. Streifer, "76 W cw monolithic laser diode arrays," Appl. Phys. Lett. 54(23), 2299-2301 (1989).

136. D. F. Welch, "A brief history of high-power semiconductor lasers," IEEE J. Sel. Top. Quantum Electron. 6(6), 1470-1477 (2000).

137. "Solid-state laser developments: diode-pumped YAG achieves $1 \mathrm{~W}$ CW," Laser Focus World 23(8), 40-42 (1987).

138. M. Ikeda, Y. Mori, H. Sato, K. Kaneko, and N. Watanabe, "Roomtemperature continuous-wave operation of an AlGaInP double heterostructure laser grown by atmospheric pressure metalorganic chemical vapor deposition," Appl. Phys. Lett. 47(10), 1027-1028 (1985).

139. A. Gomyo, K. Kobayashi, S. Kawata, I. Hino, and T. Suzuki, "Aging characteristics of $\mathrm{AlGaInP} / \mathrm{GaInP}$ visible-light lasers $(\lambda=678 \mathrm{~nm}), "$ Electron. Lett. 23(2), 85 (1987).

140. H. Amano, M. Kito, K. Hiramatsu, and I. Akasaki, "P-Type conduction in $\mathrm{Mg}$-doped $\mathrm{GaN}$ treated with low-energy electron beam irradiation (LEEBI)," Jpn. J. Appl. Phys. 28, L2112 (1989).

141. I. Akasaki, "Key inventions in the history of nitride-based blue LED and LD," J. Cryst. Growth 300(1), 2-10 (2007).

142. S. Nakamura, M. Senoh, S. Nagahama, N. Iwasa, T. Yamada, T. Matsushita, Y. Sugimoto, and H. Kiyoku, "Room-temperature continuous-wave operation of InGaN multi-quantum-well structure laser diodes," Appl. Phys. Lett. 69(26), 4056-4058 (1996).

143. S. Nakamura, G. Fasol, and S. J. Pearton, The Blue Laser Diode: The Complete Story, Springer, New York (2000).

144. C. J. Koester and E. Snitzer, "Amplification in a fiber laser," Appl. Opt. 3(10), 1182-1186 (1964).

145. R. J. Mears, L. Reekie, S. B. Poole, and D. N. Payne, "Neodymiumdoped single-mode fibre lasers," Electron. Lett. 21(17), 738-740 (1985).

146. L. Reekie, R. J. Mears, S. B. Poole, and D. N. Payne, "Tunable single-mode fiber lasers," J. Lightwave Technol. 4(7), 956-960 (1986).

147. J. Hecht, "The evolution of optical amplifiers," Opt. Photonics News 13(8), 36-39 (2002).

148. R. J. Mears, L. Reekie, I. M. Jauncey, and D. N. Payne, "High-gain rare-earth doped fiber amplifier at $1.54 \mu \mathrm{m}$," in Technical Digest, Optical Fiber Communication Conf. 1987, p. 167, Optical Society of America, Washington, D.C. (1987)

149. E. Desurvire, J. R. Simpson, and P. C. Becker, "High-gain erbiumdoped traveling-wave fiber amplifier," Opt. Lett. 12(11), 888-890 (1987).

150. R. I. Laming, M. C. Farring, P. R. Morkel, L. Reekie, and D. N. Payne, "Efficient pump wavelengths of erbium-doped fiber optical amplifier," Electron. Lett. 25(1), 12-14 (1989).

151. E. Snitzer, H. Po, F. Hakimi, T. Rumminelli, and B. C. McCollum, "Erbium fiber laser amplifier at $1.55 \mu \mathrm{m}$ with pump at $1.49 \mu \mathrm{m}$ and Yb sensitized Er oscillator," in Proc. Optical Fiber Communications Conf. Technical Digest 1988, Optical Society of America, Washington, D.C. (1988).

152. H. Taga, Y. Yoshida, N. Edagawa, S. Yamamoto, and H. Wakabayashi, " $459 \mathrm{~km}, 2.4 \mathrm{Gbit} / \mathrm{s}$ four wavelength multiplexing optical fibre transmission experiment using six Er-doped fibre amplifiers," Electron. Lett. 26(8), 500-501 (1990).

153. H. W. Etzel, H. W. Candy, and R. J. Ginther, "Stimulated emission of infrared radiation from ytterbium-activated silicate glass," Appl. Opt. 1(4), 534-536 (1962)

154. H. M. Pask, R. J. Carman, D. C. Hanna, A. C. Tropper, C. J. Mackechnie, P. R. Barber, and J. M. Dawes, "Ytterbium-doped silica fiber lasers: versatile sources for the 1-1.2 $\mu \mathrm{m}$ region," IEEE J. Sel. Top. Quantum Electron. 1(1), 2-13 (1995).

155. V. Gapontsev, V. Fomin, and A. Yusim, "Recent progress in scaling of high-power fiber lasers at IPG photonics," in Technical Digest Solid State and Diode Laser Technology Review, p. 142, Directed Energy Professional Society, Albuquerque, NM (2009). (Note: the 
printed abstract claims $6 \mathrm{~kW}$ single-mode, but $10 \mathrm{~kW}$ was announced.)

156. J. Hecht, City of Light: The Story of Fiber Optics, Revised and Expanded Edition, p. 254, Oxford University Press, New York (2004).

157. R. D. Burnham, D. R. Scifres, and W. Streifer, "Single heterostructure distributed-feedback GaAs-diode lasers," IEEE J. Quantum Electron. QE-11(7), 439-449 (1975); F. K. Reinhart, R. A. Logan, and C. V. Shank, "GaAs- $\mathrm{Al}_{x} \mathrm{Ga}_{1-x}$ As injection lasers with distributed Bragg reflectors," Appl. Phys. Lett. 27(1), 45-48 (1975).

158. Y. Suematsu, "Single-mode semiconductor lasers for longwavelength optical fiber communications and dynamics of semiconductor lasers," IEEE J. Sel. Top. Quantum Electron. 6(6), 14361447 (2000).

159. C. J. Chang-Hasnain, "Tunable VCSEL," IEEE J. Sel. Top. Quantum Electron. 6(6), 978-987 (2000).

160. L. A. Coldren, "Monolithic tunable diode lasers," IEEE J. Sel. Top. Ouantum Electron. 6(6), 988-999 (2000).

161. K. Iga, S. Ishikawa, S. Ohkouchi, and T. Nishimura, "Room temperature pulsed oscillation of GaAlAs/GaAs surface emitting junction laser" IEEE J. Quantum Electron. QE-21(6), 663-668 (1985).

162. S. W. Corzine, R. S. Geels, R. H. Yan, J. W. Scott, L. A. Coldren, and P. L. Gourley, "Efficient, narrow-linewidth distributed Bragg reflector surface-emitting laser with periodic gain," IEEE Photon. Technol. Lett. 1(3), 52-54 (1989).

163. V. Scarani, H. Bechmann-Pasquinucci, N. J. Cerf, N. Dusek, N. Lutkenhaus, and M. Peev, "The security of practical quantum key distribution," http://arxiv.org/abs/0802.4155v3, dated Sept. 30, 2009.

164. Walter Koechner, Solid-State Laser Engineering, 2nd ed., p. 336, Springer-Verlag, Berlin (1988).

165. J. Hecht, "Ray guns get real," IEEE Spectrum 46(7), 28-33 (2009)

166. http://www.textrondefense.com/news/2010/02_18_10.htm, checked Jun. 7, 2010.

167. R. F. Kazarinov and R. A. Suris, "Possibility of amplification of electromagnetic waves in a semiconductor with a superlattice," Fiz. Tekh. Poluprovodn. 5(4), 797-800 (1971).
168. J. Faist, F. Capasso, D. L. Sivco, C. Sirtori, A. L. Hutchinson, and A. Y. Cho, "Quantum cascade laser," Science 264, 553-556 (1994).

169. C. H. Li, A. J. Benedick, P. Fendel, A. G. Glenday, F. X. Kärtner, D. F. Phillips, D. Sasselov, A. Szentgyorgyi, and R. L. Walsworth, "A laser frequency comb that enables radial velocity measurements with a precision of $1 \mathrm{~cm} / \mathrm{s}^{-1}$," Nature 452 610-612 (2008).

170. G. Krauss, S. Lohss, T. Hanke, A. Sell, S. Eggert, R. Huber, and A. Leitenstorfer, "Synthesis of a single cycle of light with compact erbium-doped fibre technology," Nature Photon. 4(1), 33-36 (2010).

171. R. F. Oulton, V. J. Sorger, T. Zentgraf, R.-M. Ma, C. Gladden, L. Dai, G. Bartal, and X. Zhang, "Plasmon lasers at a deep subwavelength scale," Nature 461, 629-632 (2009).

172. http://www.extreme-light-infrastructure.eu/, checked Jun. 11, 2010

173. J. Hecht, "NIF is up and running at last," Laser Focus World $\mathbf{4 5}(11)$, 33-39 (2009)

174. B. McNeil, "First light from hard X-ray laser," Nature Photon. 3(7), 375-377 (2009).

175. “Laser marketplace 2010," Laser Focus World 46(1), 32-49 (2010).

Jeff Hecht is an independent author and consultant who has been writing about lasers and optics for 35 year. $\mathrm{He}$ is a contributing editor for Laser Focus World magazine and a correspondent for the international weekly New Scientist. His published books include Beam-The Race to Make the Laser, City of Light-The Story of Fiber Optics; Laser Pioneers; Understanding Lasers-An Entry Level Guide; Understanding Fiber Optics; The Laser Guidebook; OpticsLight for a New Age; Beam Weapons-The Next Arms Race; and Laser-Supertool of the $80 \mathrm{~s}$. He is a member of the Optical Society of America, the American Physical Society, the Institute of Electrical and Electronics Engineers, and the National Association of Science Writers. He holds a BS in electronic engineering from Caltech. His website is http://www.jeffhecht.com. 